\title{
Diagnosis and Treatment of Lichen Sclerosus
}

\author{
An Update
}

\author{
Susanna K. Fistarol · Peter H. Itin
}

Published online: 14 December 2012

(C) The Author(s) 2012. This article is published with open access at Springerlink.com

\begin{abstract}
Lichen sclerosus (LS) is a chronic, inflammatory, mucocutaneous disorder of genital and extragenital skin. LS is a debilitating disease, causing itch, pain, dysuria and restriction of micturition, dyspareunia, and significant sexual dysfunction in women and men. Many findings obtained in recent years point more and more towards an autoimmuneinduced disease in genetically predisposed patients and further away from an important impact of hormonal factors. Preceding infections may play a provocative part. The role for Borrelia is still controversial. Trauma and an occlusive moist environment may act as precipitating factors. Potent and ultrapotent topical corticosteroids still head the therapeutic armamentarium. Topical calcineurin inhibitors are discussed as alternatives in the treatment of LS in patients who have failed therapy with ultrapotent corticosteroids, or who have a contraindication for the use of corticosteroids. Topical and systemic retinoids may be useful in selected cases. Phototherapy for extragenital LS and photodynamic therapy for genital LS may be therapeutic options in rare cases refractory to the already mentioned treatment. Surgery is restricted to scarring processes leading to functional impairment. In men, circumcision is effective in the majority of cases, but recurrences are well described. Anogenital LS is associated with an increased risk for squamous cell carcinoma of the vulva or penis. This review updates the epidemiology, clinical presentation, histopathology, pathogenesis, and management of LS of the female and male genitals and extragenital LS in adults and children.
\end{abstract}

\footnotetext{
S. K. Fistarol · P. H. Itin ( $₫)$

Department of Dermatology, University Hospital Basel,

Petersgraben 4, 4031 Basel, Switzerland

e-mail: peter.itin@usb.ch

S. K. Fistarol

e-mail: susanna.fistarol@usb.ch
}

\section{Introduction}

Lichen sclerosus (LS) was described for the first time in 1887. Since then, many synonyms have been in use, notably 'Kraurosis vulvae,' 'vulvar dystrophy,' 'white spot disease,' and 'lichen sclerosus et atrophicus' or 'guttate scleroderma.' All of these terms have been abandoned and replaced by 'lichen sclerosus,' which is now used for genital and extragenital lesions. LS is a chronically relapsing disease with a potential for atrophy, destructive scarring, functional impairment, and malignant evolution. Therefore, early diagnosis, prompt treatment, and long-term follow-up of affected patients are mandatory. Spontaneous remissions are rare. LS can not be cured, but can be controlled by adequate treatment. With early treatment, long-term sequelae such as destruction of anatomic structures and progression to squamous cell carcinoma (SCC) may be prevented. For the affected patients it is essential that dermatologists, gynecologists, urologists, histopathologists, surgeons, general practitioners, and pediatricians, respectively, have a solid knowledge of the disease and will not hesitate to cooperate if required. Since LS begins with uncharacteristic symptoms, a meticulous clinical examination, raising the clinical suspicion and, if necessary, a histopathologic confirmation is required.

We searched MEDLINE for relevant papers from 2004 to 2011 using the terms 'lichen sclerosus' or 'balanitis xerotica obliterans' in association with 'epidemiology,' 'pathogenesis,' 'autoimmune,' 'genetic,' 'hormones,' 'infection,' 'borrelia,' 'children,' 'extragenital,' 'steroid,' 'pimecrolimus,' 'tacrolimus,' 'testosterone,' 'retinoid,' 'UVA1,' 'UVB,' 'photodynamic therapy,' 'malignancy,' or 'squamous cell carcinoma.' The MEDLINE search for 'lichen sclerosus' alone produced 1524 citations. 


\section{Epidemiology}

LS is a chronic, inflammatory skin disease with a distinct predilection for the anogenital region. Only $6 \%$ of LS are isolated extragenital lesions [1]. Oral LS has rarely been described [2-4]. The exact prevalence of LS is difficult to ascertain and probably underestimated, since patients with LS may present to various clinical specialities, physicians do not always recognize LS, and patients may not report symptoms because of embarrassment or because they are asymptomatic [5]. However, in 1971, Wallace [1] calculated a prevalence of $0.1-0.3 \%$ of all patients referred to a community-based dermatology department. Both female and male patients are affected and it occurs in children, and in adults. The disease may occur for the first time at any age. There is a typical bimodal onset in prepubertal children and in postmenopausal women, respectively, and in men in their fourth decade. Affected female patients clearly outnumber male patients.

Goldstein et al. [6] found a prevalence of vulvar LS in a general gynecology practice of $1.7 \%$. Powell and Wojnarowska [7] found a prevalence of LS in premenarchal girls of $0.1 \%$. Kizer et al. [8] studied a population of 153,432 male patients and found that $0.07 \%$ had a diagnosis of LS. Nelson and Peterson [9] recently calculated in a population of $42,648,923$ male patients a prevalence of only $0.0014 \%$.

\section{Disease Pathogenesis}

The etiology of LS has not yet been adequately explained, but there is increasing evidence that autoimmune mechanisms play a pathogenetic role. There appears to be a genetic susceptibility to LS. The chronic irritant effects of urinary contact are suggested to be provocative. No infectious agent has been consistently linked to LS.

\subsection{Autoimmunity}

In common with many autoimmune diseases, LS is more prevalent in female patients. A large study of 350 women with LS revealed that $21.5 \%$ had one or more autoimmune-related diseases, $21 \%$ had a family history of autoimmune disease, and $42 \%$ had autoimmune antibodies [10]. The most common autoimmune diseases in this group were autoimmune thyroiditis (12\%), alopecia areata ( $9 \%)$, vitiligo $(6 \%)$, and pernicious anemia $(2 \%)$. These disorders should be considered in patients with LS [11]. In a LS cohort of 190 women, Cooper et al. [12] found $28 \%$ had one or more associated autoimmune diseases compared with $9 \%$ of 230 control patients. Thyroid disease was the most prevalent autoimmune disorder occurring in $16 \%$ of the LS cohort versus $8 \%$ of controls. Birenbaum and Young [13] found that the prevalence of thyroid disease in 211 women with biopsy-proven LS was $30 \%$. In comparison, in the general population of Scotland, Leese et al. [14] observed in 2001 an overall prevalence of thyroid dysfunction of $3.8 \%$. Female patients showed a prevalence of $6.4 \%$ and male patients showed a prevalence of $1.1 \%$.

In a group of 30 prepubertal girls with anogenital LS, $6.6 \%$ had an associated autoimmune disease (vitiligo and alopecia areata), and $56 \%$ of their parents or grandparents did [15].

In men, the association with autoimmune disease is weaker. In a study of 35 men with LS, $6 \%$ had an associated autoimmune disease and $19 \%$ had a positive family history for autoimmune disease [16]. Another study showed that only $3 \%$ of 58 men with LS had a personal history of autoimmune disease, and $10 \%$ had a first-degree relative with an autoimmune disease [17]. In a case-control study, 73 men with LS were compared with 219 controls. Vitiligo (12\% vs. $0 \%$ ) and alopecia areata (12\% vs. $1 \%$ ) were significantly more common in patients than in controls. A family history of diabetes mellitus, vitiligo, alopecia areata, or thyroid disease and the presence of other autoimmune diseases were identified as risk factors for male LS [18].

Circulating IgG autoantibodies targeting extracellular matrix 1 (ECM1) protein have been demonstrated in the sera of $74 \%$ of women with anogenital LS compared with $7 \%$ in controls [19]. ECM1 autoreactivity was more likely in individuals whose disease duration was greater than 1 year and/or in those with more extensive disease, suggesting that ECM1 autoreactivity might be involved in the progression rather than in the initiation of the disease. Also, in men, the anti-ECM1 antibody concentrations were significantly higher in men with LS than in controls [20]. The authors propose that chronic irritation of the genital epithelium may lead to previously sequestered site-specific skin epitopes being revealed and that those patients with an autoimmune diathesis would subsequently be more likely to develop antibodies. They suggest that ECM1 autoimmunity might be an epiphenomenon rather than being directly pathogenic [20]. The human ECMI gene was isolated in 1997. Since then, several important biologic functions have been attributed to the glycoprotein ECM1. Within the epidermis, ECM1 has a role in the control of keratinocyte differentiation. Within the dermis, ECM1 has a role in the structural organization of the dermis, binding to perlecan, matrix metalloproteinase-9, and fibulin. ECM1 helps to regulate basement membrane and interstitial collagen fibril macro-assembly and growth factor binding. It stimulates proliferation of endothelial cells and induces angiogenesis. In 2002, loss-of-function mutations in the ECM1 gene were discovered to cause lipoid proteinosis 
(OMIM 247100), also known as Urbach-Wiethe disease or hyalinosis cutis et mucosae, a rare autosomal recessive genodermatosis, clinically characterized by skin and mucosal infiltration and scarring, and histologically by disruption/duplication of the basement membrane and widespread deposition of hyaline material in the dermis. ECM1 shows overexpression in certain malignancies and is abnormally expressed in chronologically aged and photoaged skin [21].

Antibodies targeting the basement membrane zone (BMZ) [BP180 and BP230] have been found in one-third of patients with vulval LS [22]. Baldo et al. [23] demonstrated that in $43 \%$ of their vulval LS patients the NC16A domain of BP180 is a target for circulating T cells, and there are associated autoantibodies to BP180. In girls with vulvar LS, a prevalence of $45 \%$ (4/9) of circulating BMZ autoantibodies was found [24]. However, in the most recent study concerning this topic only $3.4 \%$ of 149 LS patients, compared with $94.7 \%$ of 38 bullous pemphigoid patients and $0 \%$ of 36 healthy controls had elevated anti-BMZ antibodies, producing no significant difference between LS patients and controls [25] so that the pathogenetic role of $\mathrm{BMZ}$ antibodies remains uncertain.

\subsection{Genetic Factors}

A large, observational, cohort study of a total of 1052 women with vulval LS showed that $12 \%$ had a positive family history of LS [26], indicating that familial cases of LS probably have been underreported so far. Patients with familial LS had more often associated autoimmune disease (7\%) than patients with sporadic LS (5\%), although this increase was not statistically significant [26]. A genetic predisposition seems likely.

Human leukocyte antigen (HLA) DQ7 has been shown to occur more frequently in both women and men with LS [15, 17, 27]. HLA DQ8 and DQ9 have been found more frequently in women with LS than in controls [26]. Associations between LS and HLA -B*08-B*18 [28], -B*15, $-\mathrm{B} * 57,-\mathrm{CW} * 03,-\mathrm{CW}^{*} 07,-\mathrm{CW}^{*} 18,-\mathrm{DRB} 1 * 04,-\mathrm{DRB} 4 *$, -DRB1*07 [29], -DRB1*12 and the haplotype DRB1*12/ DQB1*0301/04/09/010 have been documented [30]. HLA DR11 and DR12 were more common in men with LS [16].

\subsection{Trauma and Chronic Irritation}

Genital LS is described to occur in patients with genital jewellery and after surgery, trauma, and instrumentation, and does recur in grafts and circumcision scars [31]. It is very uncommon that a man circumscribed at birth will develop LS. So it seems likely that the occlusive, moist environment under the prepuce is permissive for the development of genital LS. Chronic exposure to urine has been implicated as a causative factor for genital LS [32, 33]. Edmonds and Bunker [34] used high-resolution nuclear magnetic resonance spectroscopy to investigate potential alterations in urinary constituents in male genital LS. They identified creatinine, citrate, hippurate, dimethylamines, trimethylamines, alanine, and bile acids. No significant differences were found between the urine samples of men with and without genital LS.

\subsection{Infections}

\subsubsection{Borrelia burgdorferi}

Previous studies based on serologic tests, culture, immunohistochemistry, and polymerase chain reaction (PCR) reported conflicting results concerning the role of Borrelia in the pathogenesis of LS. Borrelia species have been detected in cases from Europe, but not from the USA.

Edmonds et al. [35] tested sera from 30 adult male patients with genital LS and from 32 aged-matched controls by IgG Western blotting. All of the LS patients tested negative and one of the controls had a positive serology.

By immunoperoxidase reaction, Aberer et al. [36, 37] detected Borrelia burgdorferi in $47 \%(7 / 15)$ of their LS patients. Studies from Europe using PCR approaches revealed positive results ranging from 0 to $100 \%$ [38-46], taking those studies together positive results were obtained in this way in $34 \%(28 / 83)$.

Using focus-floating microscopy (FFM), Borrelia species were found in $63 \%$ (38/60) of cases of LS compared with $90 \%$ of positive controls of classic borreliosis and $0 \%$ of negative controls [45]. In these patients, Borrelia species were detected significantly more often in early inflammatory-rich $(80 \%, 31 / 39)$ than in late inflammatorypoor $(33 \%, 7 / 21)$ cases. Eleven skin biopsies of patients from the same patient group were also examined by PCR. Remarkably, none of the 11 samples was positive for Borrelia by PCR, while 6 of 10 out of the same 11 cases were positive by FFM [45], indicating the difficulties of the various techniques to reliably detect Borrelia in tissue specimens.

\subsubsection{Epstein-Barr Virus}

In a preliminary study, Epstein-Barr virus (EBV) DNA was found in $26.5 \%$ of 34 vulvar biopsies of patients with LS compared with $0 \%$ in controls [47]. Future studies have to elucidate whether EBV actually plays a role in cases of LS.

\subsection{Hormonal Influences}

Serum levels of dihydrotestosterone were found to be significantly decreased in patients with untreated vulvar 
LS. These results seemed to suggest that decreased $5 \alpha$-reductase activity was an etiologic factor for LS [48].

Moreover, immunohistochemical evaluation of androgen receptors in genital and extragenital LS provided evidence for the loss of androgen receptors with disease progression in lesional skin [49]. Treatment with topical testosterone in the past, based on those findings, has been abandoned for lack of evidence for its effectiveness [5].

Günthert et al. [50] retrospectively analyzed the data of 40 premenopausal patients with early-onset LS in a casecontrol study with a matched control group of 110 healthy women to find potential risk factors for early-onset vulvar LS focussing on the use of oral contraceptives (OCPs). One hundred percent of the LS patients were using OCPs compared with $66.4 \%$ in the control group. OCPs with antiandrogenic activity were used by $70 \%$ of the LS patients and by $48 \%$ of the women using OCPs in the control group, suggesting that disturbance of the androgendependent growth of the vulvar skin by OCPs and especially by OCPs with antiandrogenic properties might trigger the early onset of LS in a subgroup of susceptible young women.

\section{Natural Course}

In male and female patients, LS is usually a scarring, chronic progressive or relapsing and remitting, lifelong condition. There are few publications referring to the longterm follow-up of LS patients. Nevertheless, it is well known that LS in adult women may cause significant alteration in vulvar architecture. The labia minora may become reabsorbed and fused, and the clitoris entrapped under scar tissue. The vaginal introitus may become stenotic and narrowed. In men, the frenulum often becomes contracted and circumferential involvement of the preputial aperture leads to a progressive fibrous phimosis. The surface of the glans and inner prepuce may ulcerate. Subsequent fibrosis may lead to dense fusion of the layers. Urethral involvement starts at the meatus. In long-standing disease, meatal stenosis may progress to involve the entire length of the urethra spreading proximally as far back as the prostate [51].

Less commonly, genital LS may be complicated by SCC.

One prospective case series reported on a cohort of 12 girls with prepubertal LS followed up for to 10 years until adolescence. Twenty-five percent had complete remission, whereas $75 \%$ remained symptomatic and showed definite physical signs of LS when examined as adolescents [52]. Fifty percent of the children experienced distortion in vulvar architecture, including loss of labia minora and clitoral substance. A previous study followed 21 girls who developed LS before puberty examining the clinical course after puberty [53]. In postpuberty, $52 \%$ still experienced occasional pruritus, requiring intermittent topical corticosteroid application, and definite physical signs persisted in $76 \%$.

\section{Diagnosis}

The diagnosis of LS is usually clinical. When the clinical features are typical, histologic examination is not always essential. However, in the early stages of the disease the diagnosis can be difficult. The main differential diagnoses are lichen planus (LP), lichen simplex chronicus, vitiligo, immunobullous disorders such as mucous membrane pemphigoid and vulvar or penile intraepithelial neoplasia $[11,54]$. In clinically inconclusive cases, a histologic examination is advisable and might close the gap, but should never be interpreted in isolation. One-third of men having sufficient symptoms and signs to be clinically diagnosed with LS, showed only nonspecific histology on biopsy or in the circumcised prepuce [20]. A nonspecific biopsy does not rule out LS, but classic histologic findings confirm the diagnosis [11]. Patients under routine followup will need a biopsy if: (1) there is a suspicion of neoplastic change, i.e., a persistent area of hyperkeratosis, persistent erosion, or erythema, or new warty or papular lesions; (2) there is an area resistant to adequate treatment; (3) there is extragenital LS, with features suggesting an overlap with morphea; (4) there are pigmented areas, in order to exclude an abnormal melanocytic proliferation; and (5) second-line therapy is to be used [5].

There are instances when it can be impossible to differentiate between LS and LP either on the basis of the clinical or the histologic features (Table 1). These cases are described as overlap syndrome and often show poor response to treatment [5].

\subsection{Clinical Features}

\subsubsection{Female Anogenital Lichen Sclerosus (LS): Adults}

Meyrick Thomas et al. [10] studied 350 women with clinically typical and histologically confirmed LS. The mean age at onset of symptoms was 45.5 years. In $9 \%$ of women the onset of LS was in prepuberty, in $41 \%$ in the reproductive years, and in $50 \%$ postmenopause. Cooper et al. [55] studied a total of 253 women and 74 girls with the typical clinical features of vulvar LS. Twenty-three percent of the patients were premenarchal, $17 \%$ in their reproductive years, and $60 \%$ postmenopausal. The mean age at onset of symptoms was 5.4 years for girls and 55.1 years for women. The mean age at diagnosis was 7.6 years for girls and 60 years for women. 
Table 1 Distinguishing features between lichen sclerosus and lichen planus

\begin{tabular}{|c|c|c|}
\hline Features & Lichen sclerosus & Lichen planus \\
\hline $\begin{array}{l}\text { Cutaneous } \\
\text { involvement }\end{array}$ & Rare & Often \\
\hline $\begin{array}{l}\text { Involvement of } \\
\text { vaginal } \\
\text { epithelium }\end{array}$ & No & Yes \\
\hline $\begin{array}{l}\text { Perianal } \\
\text { involvement }\end{array}$ & $\begin{array}{l}\text { Often in women, } \\
\text { not in men }\end{array}$ & Rare \\
\hline $\begin{array}{l}\text { Involvement of } \\
\text { oral mucosa }\end{array}$ & Very rare & Common \\
\hline Nail dystrophy & No & Occasionally \\
\hline $\begin{array}{l}\text { Most common } \\
\text { presenting } \\
\text { symptom }\end{array}$ & Itch & Soreness, pain \\
\hline Dyspareunia & Common & Common \\
\hline $\begin{array}{l}\text { Primary } \\
\text { efflorescence }\end{array}$ & Lichenoid papule & Lichenoid papule \\
\hline Erosions & Yes & Yes \\
\hline Sclerosis & Yes & No \\
\hline Scarring & Yes & Yes \\
\hline Introital stenosis & Rare & Often \\
\hline $\begin{array}{l}\text { Narrowing of } \\
\text { the meatal } \\
\text { opening and } \\
\text { phimosis }\end{array}$ & Yes & No \\
\hline $\begin{array}{l}\text { Other common } \\
\text { clinical } \\
\text { features }\end{array}$ & $\begin{array}{l}\text { Depigmentation, } \\
\text { atrophy, hemorrhages }\end{array}$ & White reticulate striae \\
\hline Histology & $\begin{array}{l}\text { Epidermal atrophy, } \\
\text { follicular plugging, } \\
\text { homogenized } \\
\text { collagen in upper } \\
\text { dermis with dermal } \\
\text { edema, lichenoid } \\
\text { lymphocytic infiltrate }\end{array}$ & $\begin{array}{l}\text { Lichenoid lymphocytic } \\
\text { infiltrate, epidermal } \\
\text { acanthosis with } \\
\text { sawtooth appearance, } \\
\text { wedge-shaped } \\
\text { hypergranulosis, } \\
\text { colloid bodies }\end{array}$ \\
\hline $\begin{array}{l}\text { Associated } \\
\text { squamous cell } \\
\text { carcinoma }\end{array}$ & Yes & Yes \\
\hline
\end{tabular}

The area involved may vary from a small, single area (Fig. 1) to the entire region of vulva, perineum, and perianus. There may be extension to the genitocrural folds, buttocks, and thighs (Fig. 2). The characteristic sites involved are the interlabial sulci, labia minora and labia majora, clitoris and clitoral hood, and perineum and perianal area, giving rise to the characteristic 'figure-of-eight' shape (Fig. 3). Genital mucosal involvement does not occur, the vagina and cervix always being spared, in contrast to LP [5]. A retrospective chart review of 81 consecutive patients with LS showed that almost all of the affected women had labial involvement, with concomitant involvement of the clitoris (70\%), perineum (68\%), and perianal region $(32 \%)$ [56]. Similar results were obtained

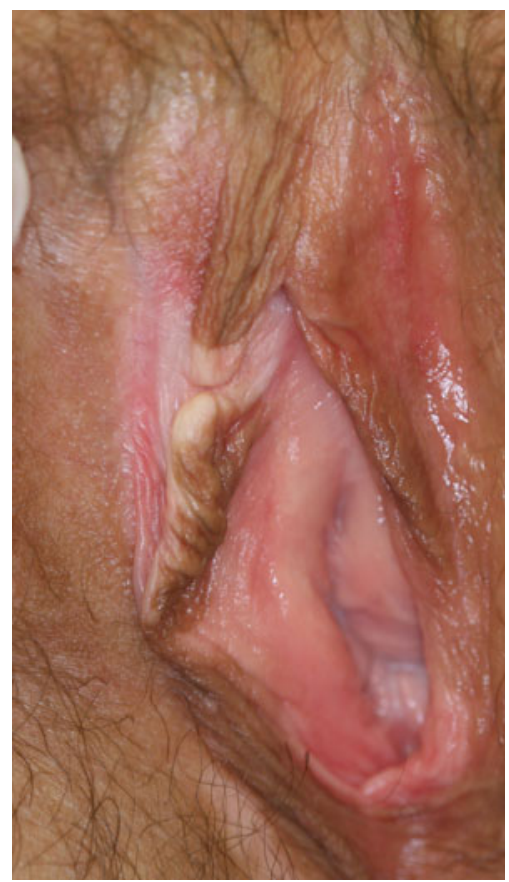

Fig. 1 A 41-year-old woman with asymmetric vulvar lichen sclerosus limited to the upper part of the right labium minus and the interlabial sulcus: depigmentation, hyperpigmentation, and sclerosis leading to circumscribed retraction of the right labium minus

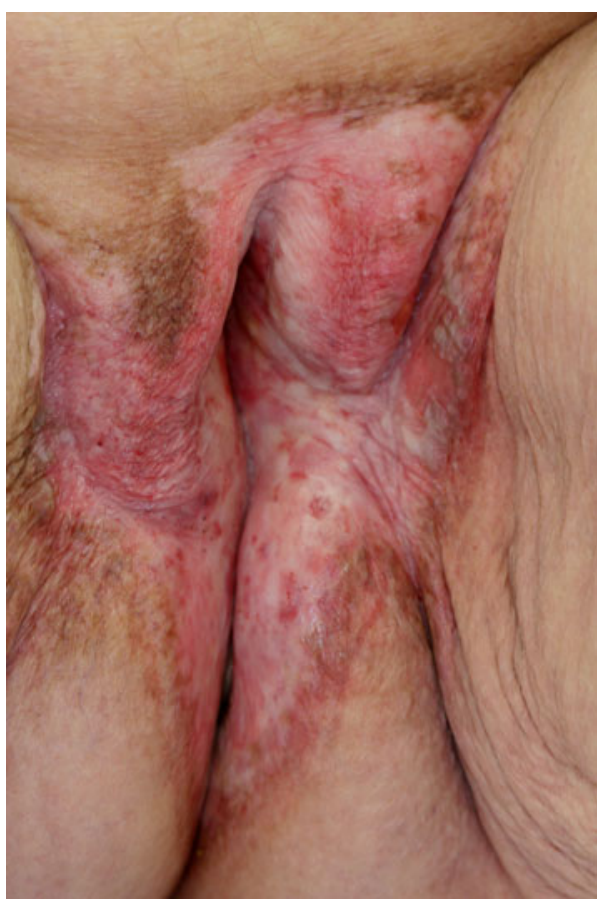

Fig. 2 An 80-year-old woman with extensive, long-standing, anogenital lichen sclerosus affecting the entire vulva, perineum, perianal region, genitocrural folds, inner thighs, and buttocks: depigmentation, hyperpigmentation, erythema, sclerosis, erosions, telangiectasias, and complete loss of labia minora 


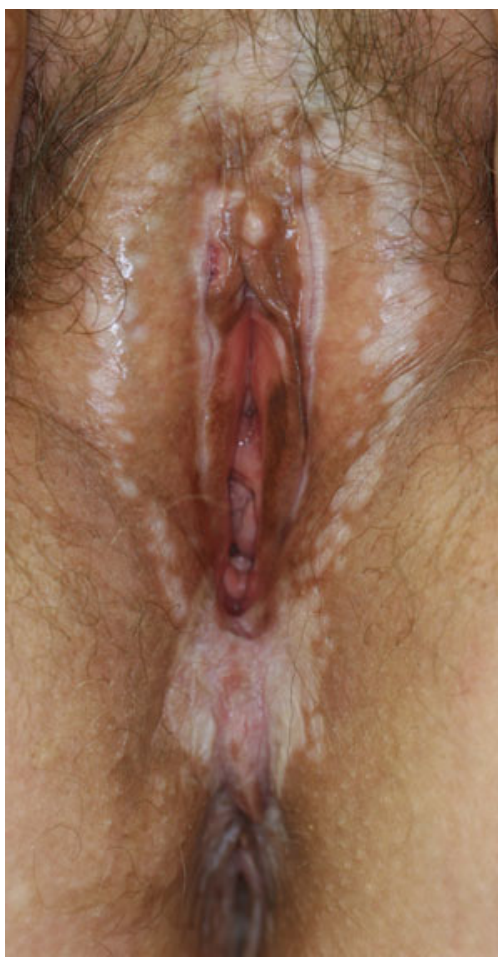

Fig. 3 A 65-year-old woman with lichen sclerosus showing the characteristic 'figure-of-eight' distribution: typical primary lesions are the ivory-white, flat, polygonal papules, giving lichen sclerosus the name 'white-spot-disease' in the past. Note the involvement of the interlabial sulci, clitoris, and clitorial hood

by Simpkin and Oakley [57] in their clinical review of 202 affected women. Labia minora was affected in $87 \%$ of women, perineum in $85 \%$, clitoris in $72 \%$, and the perianal region in $50 \%$. LS can koebnerize and may first arise in an episiotomy scar. Extragenital lesions are seen more frequently in women than men, and occurred in $11 \%$ of the 327 female patients examined by Cooper et al. [55], in $13 \%$ of the 357 female patients examined by Meyrick Thomas et al. [58], and in $13 \%$ of the women reviewed by Simpkin and Oakley [57].

Vulvar LS often begins around the periclitoral hood with a sharply demarcated, slightly elevated, nonspecific erythema (Fig. 4), progressing to the labia minora, vestibule, and perineal and perianal regions. Edema, particularly of the periclitoral hood, may be prominent. Fragility is a hallmark of LS, becoming manifest in erosions, fissuring, purpura, and ecchymoses. Fissuring is especially common between the clitoris and urethra, in the interlabial sulci, and at the base of the posterior fourchette (Fig. 5). Tearing during sexual intercourse or physical examination is common. The typical lesions are porcelain-white papules and plaques with follicular delling and hyperkeratosis (Fig. 3). The area evolves into a dry, hypopigmented, sclerotic, and later atrophic lesion. The resulting crinkling or cellophane

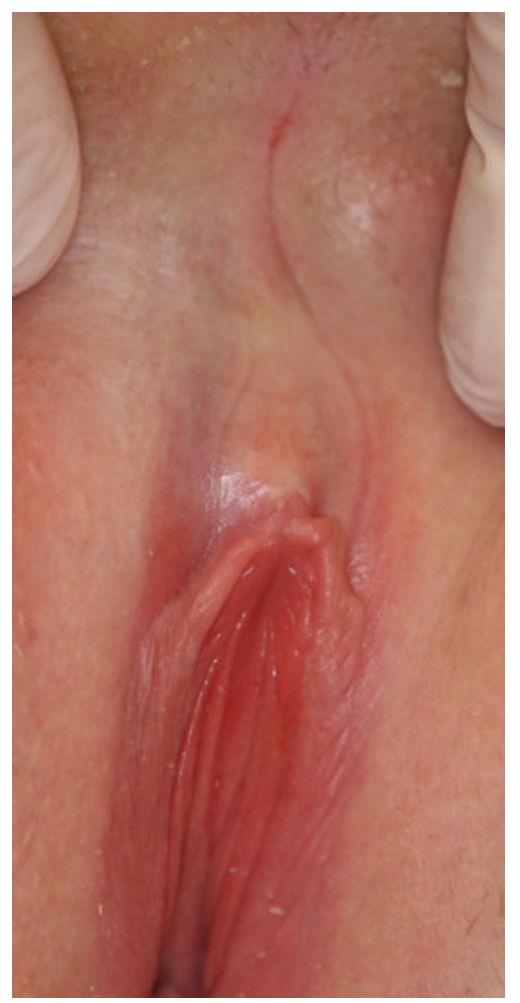

Fig. 4 A 17-year-old woman with lichen sclerosus affecting primarily the periclitorial region: the periclitorial hood is sealed and the clitoris buried. Fissure in the upper part of the periclitorial hood and diffuse erythema of the vestibule

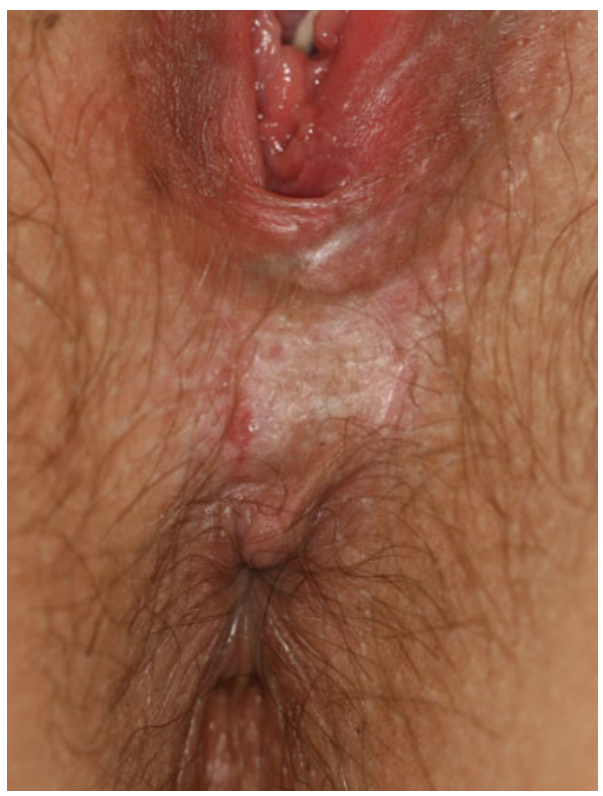

Fig. 5 A 27-year-old woman with lichen sclerosus affecting the vulva and perineum: perineal pallor, sclerosis, and sagittal fissure

paper-type appearance is pathognomonic. LS is a scarring process and may cause complete loss of the labia minora, sealing of the clitoral hood, and burying of the clitoris 


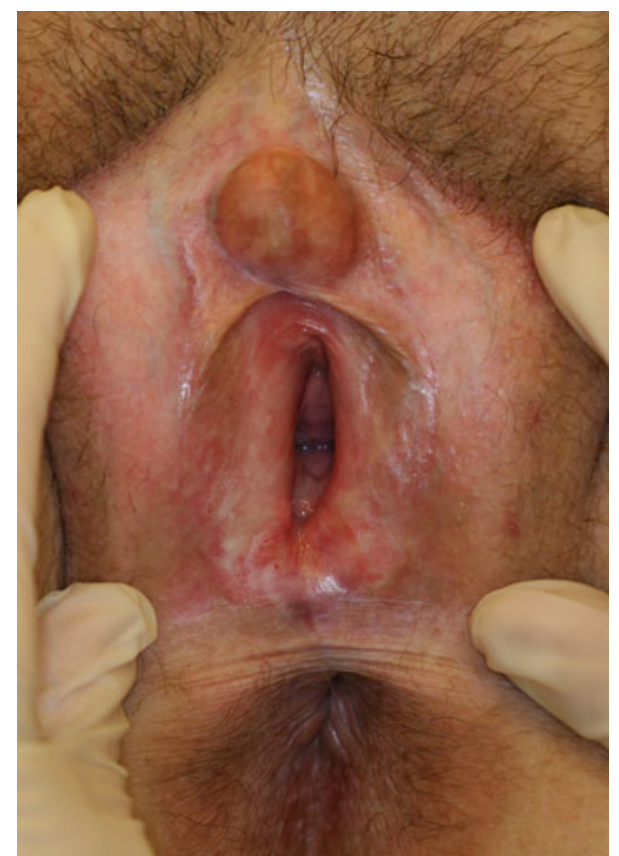

Fig. 6 A 47-year-old woman with vulvar lichen sclerosus: diffuse pallor, erythema, sclerosis, and telangiectasias, almost complete loss of labia minora and smegmatic pseudocyst resulting from adhesions of the clitorial hood

(Fig. 4). Smegmatic pseudocyst can result from adhesions of the clitoral hood (Fig. 6) [54]. Fusions of tissue may occur across the midline, rarely leading to problems with micturition. Severe introital narrowing interfering with intercourse may rarely occur, but is seen more frequently in the LS /LP overlap syndrome (Fig. 7) [5].

Vulvar melanosis can result from chronic disease. Genital lentiginosis frequently presents with dark brownblack macules with variegated pigmentation and irregular borders. Genital nevi occasionally exhibit similar characteristics particularly in the context of chronic inflammation and LS. Histologic examination can easily differentiate mucosal lentiginosis from melanoma, but melanocytic nevi superimposed on a background of anogenital LS, both clinically and histologically, may mimic malignant melanoma [59]. Clark et al. [60] reported that more than onethird of genital nevi sent to them in consultation (20/56) had previously been misdiagnosed as melanoma. Histologic interpretation is particularly difficult in the setting of LS, when papillary dermal melanocytes entrapped in sclerosis often display cytologic atypia and the lymphocytic infiltrates can disrupt dermal nests. Carlson et al. [61] identified ten melanocytic lesions clinically suspected to be malignant melanoma or atypical melanocytic nevi arising in anogenital LS of the vulva and perineum. The suggestive clinical symptoms or signs were irregular borders, black clinical appearance, recent growth, and/or recent onset of pruritus. Melanocytic proliferations arising in LS were

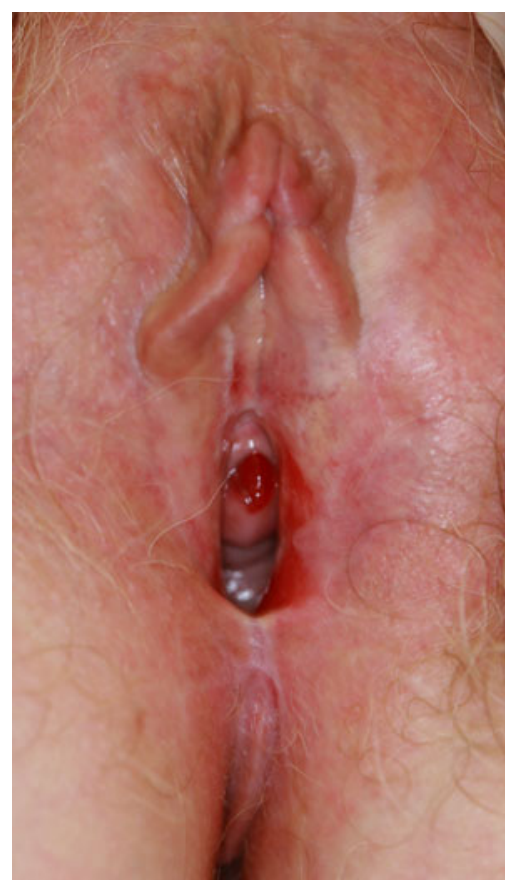

Fig. 7 A 75-year-old woman with lichen sclerosus/lichen planus overlap syndrome: diffuse pallor, erythema, sclerosis, and telangiectasias. Damage of the normal architecture with partial loss of labia minora. Edema of the clitoris and the residual labia minora. Introital erosions and narrowing of the introitus. Sagittal fissuring of the perineum. Coincidental finding is an urethral caruncle

interpreted histologically as junctional melanocytic nevi (five cases), compound melanocytic nevi (three cases), intradermal melanocytic nevi (two cases), or malignant melanoma (one case). Single cases of vulvar melanoma in the setting of LS have been described, but are a rarity. Vulvar pigmented lesions associated with LS are almost always benign. Nevertheless, clinically suspicious pigmented lesions should be biopsied.

Itch is the main symptom, often worse at night and sufficiently severe to disturb sleep. Chronic scratching leads to subepithelial hemorrhage and superimposed lichen simplex (Fig. 8). Pain, soreness, and dysuria may be a consequence of erosions or fissures. A high proportion of women of all ages reported that LS led to significant sexual problems including dyspareunia and apareunia due to continuing inflammatory disease as well as due to anatomic changes and scarring from long-standing active disease $[44,62]$. Under treatment with clobetasol propionate ointment, the Female Sexual Distress Scale score could be reduced from 29 pretreatment to 15 post-treatment, and with pimecrolimus cream from 27 pretreatment to 21 posttreatment [63]. Though adequate treatment will improve sexual problems, women with LS continue to have significant sexual dysfunction. Disease severity does not always correlate with severity of symptoms. LS may be entirely asymptomatic and an incidental finding on examination. 


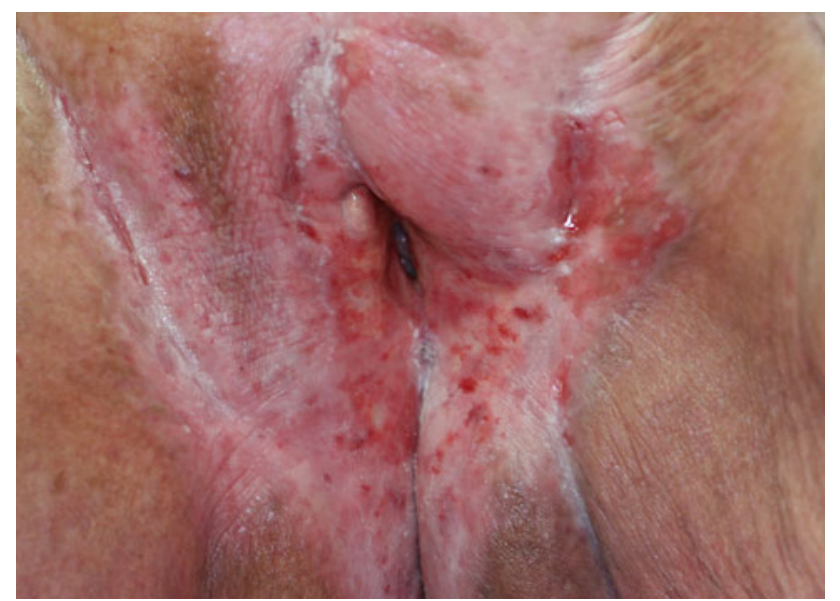

Fig. 8 An 81-year-old woman with lichen sclerosus with superimposed lichen simplex: marked lichenification and excoriations, ecchymoses, telangiectasias, erosions, and ulceration on a hypopigmented and erythematous background. Fissuring of the right genitocrural fold. Complete loss of normal vulvar architecture

Vulvar dysesthesia may persist in spite of clinical control of the disease.

\subsubsection{Female Anogenital LS: Children}

In 70 cases of LS in girls, the mean age at development of symptoms was 5.0 years (range 1-12 years) and the mean age at diagnosis was 6.7 years (range 3-14 years) [7]. The most common presenting symptoms were itching (72\%) and soreness $(61 \%)$. Pain on defecation presenting as constipation and bowel symptoms ( $24 \%)$, dysuria (24\%), and local bleeding $(26 \%)$ is seen significantly more frequently in girls than in women [55]. The skin may appear bruised with purpura and ecchymoses (Fig. 9). In the presence of hemorrhagic lesions, LS in girls can be mistaken for sexual abuse [54]. However, the verification of a diagnosis of LS does not exclude coincident sexual abuse, since LS may be triggered by sexual abuse through the Koebner phenomenon. Suspicion should be entertained when LS arises in older prepubertal girls, if response to treatment is poor, and in the case of associated sexually transmitted infections [5].

Infantile perineal protrusion (IPP) occurs almost exclusively in prepubertal girls and may be associated with LS in a minority of patients [64]. IPP appears as a pyramidal softtissue protrusion with a tongue-like lip in the midline just anterior to the anus. IPP with clinical and histologic features of LS has been described. LS may appear concurrently with IPP or may develop subsequently.

LS may improve symptomatically but usually does not entirely resolve at puberty. A retrospective study of 21 postpubertal girls with LS presenting prepubertally revealed that the disorder appeared less active in most

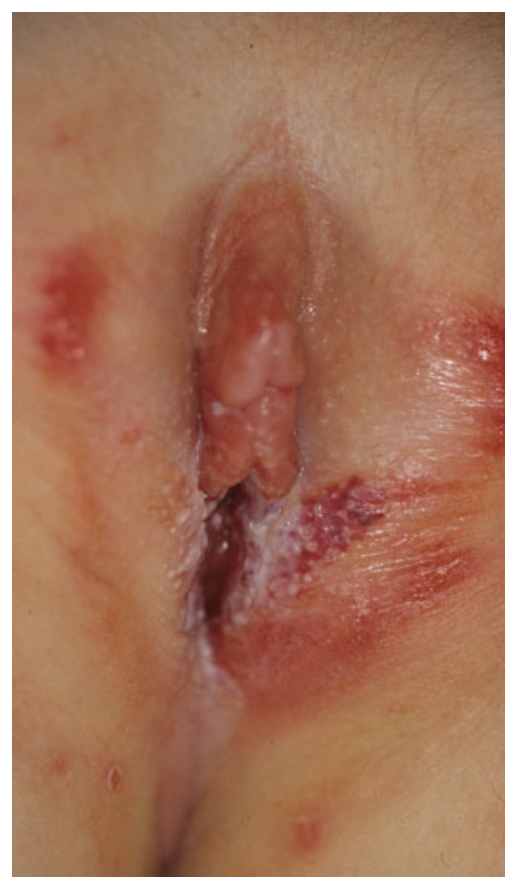

Fig. 9 A 6-year-old girl with anogenital lichen sclerosus: slight sclerosis of the clitorial hood and the inner aspect of labia majora. Prominent contusiform hemorrhage

cases, but definite physical symptoms and signs persisted in $76 \%$ [53]. A prospective follow-up of 12 children with LS showed that $25 \%$ achieved complete remission prior to menarche. Seventy-five percent of the girls had active LS at puberty and required maintenance therapy after menarche. Fifty percent had significant disturbance of vulvar architecture [52].

\subsubsection{Male Genital LS: Adults}

Nelson and Peterson [9] found the highest prevalence of LS in men at ages 61 years or older, but Edmonds et al. [33] found an adult peak late in the fourth decade. They identified retrospectively a total of 329 patients with a clinical diagnosis of male genital LS from a dermatology-centered multidisciplinary setting. Only $6 \%$ of the affected men were circumcised at presentation. LS is a disease of the uncircumcised man. In $70 \%$ of men LS involved the prepuce, in $60 \%$ the glans, and in $40 \%$ both the glans and prepuce were affected. Seventeen percent had meatal/urethral involvement. Urethral involvement usually starts at the meatus and postinflammatory scarring may lead to meatal and urethral stenosis and obstruction, complications that frequently necessitate surgical management. Only $1.5 \%$ had extragenital involvement and none had perianal involvement. In a review of 522 male patients with LS, Depasquale et al. [51] found that the disease was limited to the prepuce and glans in $57 \%$ of patients, meatal involvement occurred in $4 \%$, and urethral involvement in $20 \%$. 
Early manifestations are greyish or bluish-white discolorations of the glans and/or the inner surface of the prepuce (Fig. 10), sometimes with considerable telangiectasia. Itch may be present. Subsequently, skin thins, sclerotic plaques appear, and the prepuce becomes tightened and nonretractile. Phimosis with the risk of paraphimosis develops (Fig. 11). One report documents that $14 \%$ of primary (congenital) phimosis occurring in young adults and $40 \%$ of secondary (acquired) phimosis in older patients were due to progressive LS [65]. The involved inelastic skin is prone to fissuring during sexual activity. Purpura, bullae, erosions, and ulcerations may be encountered (Figs. 12, 13). Fifty-five percent of affected men report sexual symptoms as painful erections and erectile dysfunction [33]. Eighteen percent report urologic symptoms such as dysuria, narrowing of the urinary stream, and poor urinary flow. Twenty-nine percent are asymptomatic [33].

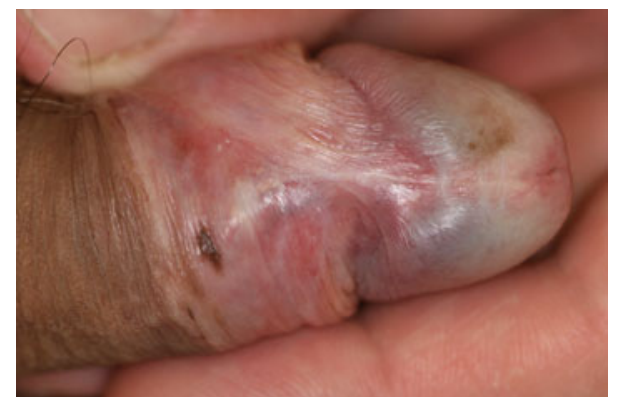

Fig. 10 A 37-year-old man with genital lichen sclerosus: grayishbluish, white discoloration of the glans and inner surface of the prepuce, sclerosis of the frenulum, and freckled melanosis

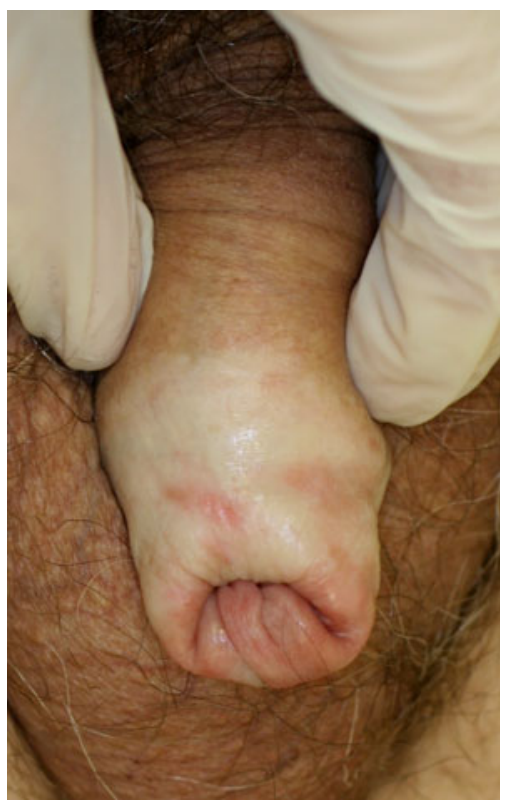

Fig. 11 A 65-year-old man with genital lichen sclerosus: depigmentation, macular erythema, and severe sclerosis leading to phimosis

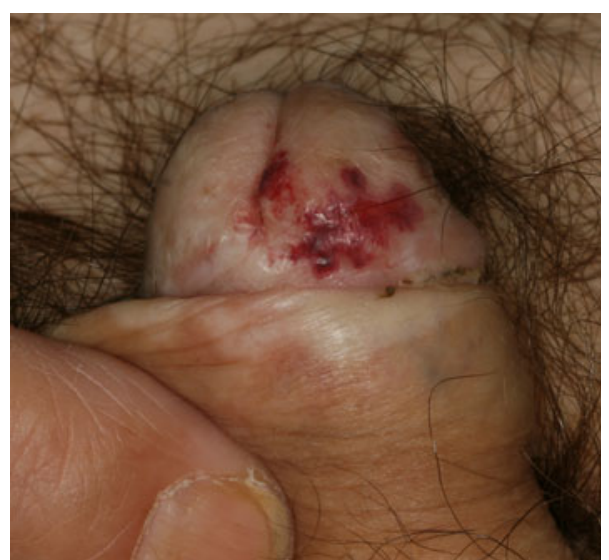

Fig. 12 A 57-year-old man with genital lichen sclerosus: depigmentation, atrophy of the glans with crinkling appearance, ecchymoses, and macular melanosis

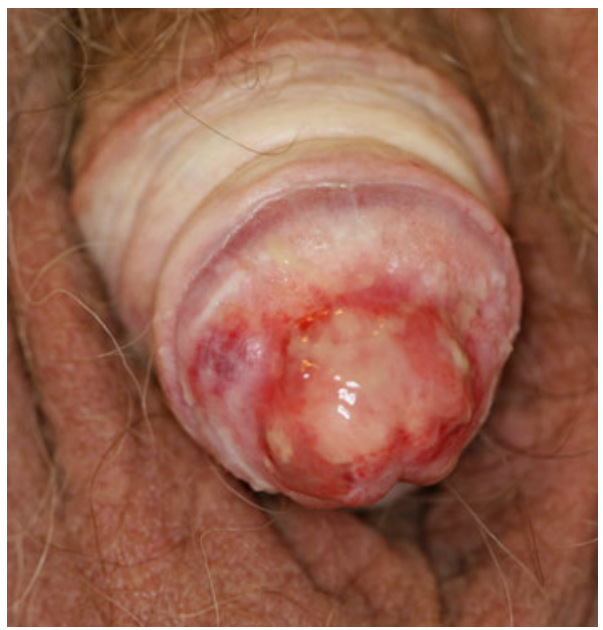

Fig. 13 A 73-year-old man with genital lichen sclerosis: severe sclerosis, scarring of the coronal sulcus, and large ulceration of the glans

\subsubsection{Male Genital LS: Children}

Boys most commonly present in need of circumcision because of associated phimosis [66]. The reported incidence of LS in boys undergoing circumcision for phimosis ranges from 10 to $40 \%$ [67-69]. A prospective study of 1,178 boys presenting with phimosis found that $40 \%$ had LS on circumcision pathology, with the highest incidence in boys aged 9-11 years (76\%) [69]. Perianal involvement, as in adult men, is extremely rare.

\subsubsection{Extragenital LS}

The most common locations for extragenital disease are the buttocks, thighs, breasts, submammary area, neck, back and chest, shoulders, axillae, and wrists. Extragenital LS 
lesions are prone to koebnerization and may express themselves in areas of physical trauma, continuous pressure, and scarring. Lesions begin as polygonal, bluishwhite, slightly elevated papules (Fig. 14). Papules coalesce into plaques, which with time become increasingly atrophic and get a wrinkled surface (Fig. 15). Telangiectasias and follicular plugging may become prominent (Fig. 16). The fragility of the flattened epidermal-dermal interface may give rise to bullous and hemorrhagic lesions. Extragenital LS is much less symptomatic than genital LS, underlining the role of occlusion and maceration in the etiology of pruritus, soreness, and pain in genital LS.

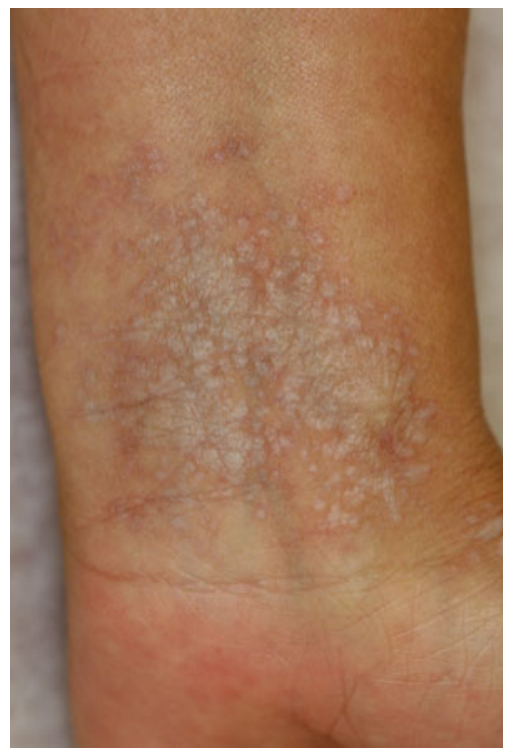

Fig. 14 A 65-year-old woman (same patient as in Fig. 3) with genital and extragenital lichen sclerosus on the volar aspects of the wrists: characteristic bluish-white, polygonal, slightly elevated papules coalescing into plaques

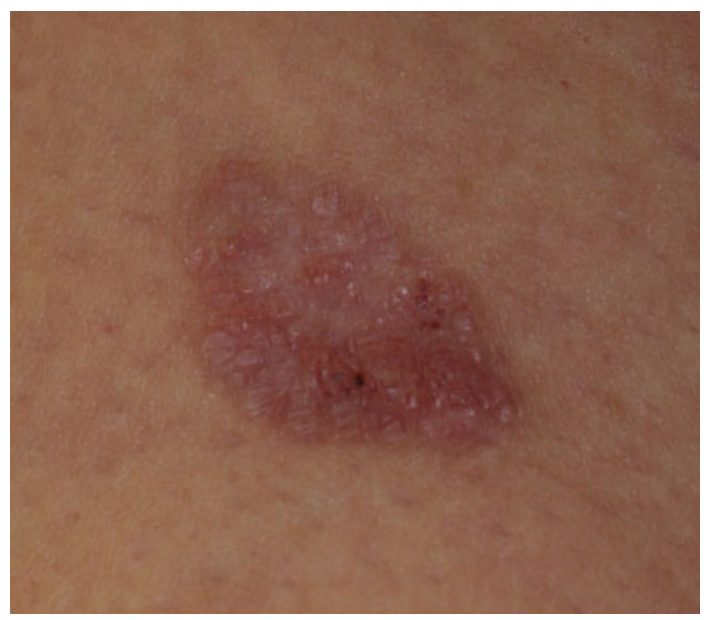

Fig. 15 An 81-year-old woman with genital and extragenital lichen sclerosus on the upper thighs: papular, partially atrophic lesion with wrinkled surface, telangiectases, and hemorrhage

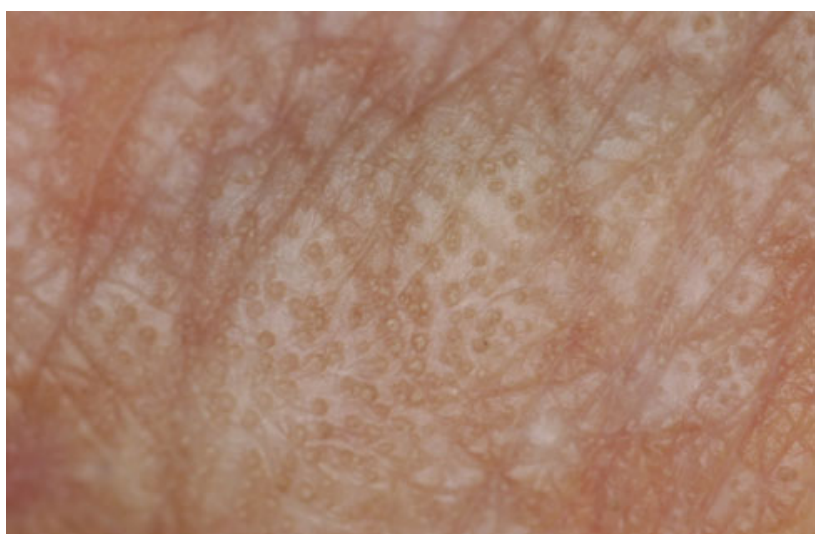

Fig. 16 A 65-year-old woman with extragenital LS on the volar aspect of the wrist (same patient as in Fig. 3 and Fig. 14) with prominent follicular plugging

\subsection{Histopathology}

In the early stages of LS not only the symptoms and clinical signs, but also the histologic picture may be uncharacteristic [70]. The histologic features in early LS are quite subtle and may overlap with those seen in psoriasis or LP, with luminal hyperkeratosis and hypergranulosis of the adnexal structures, mild irregular, occasionally psoriasiform acanthosis, and focal basement membrane thickening. Early dermal changes are subepithelial edema, homogenized collagen, and dilated blood vessels immediately under the basement membrane. The lymphocytic infiltrate can be lichenoid or interstitial with epidermal lymphocyte exocytosis and lymphocytic/lymphohistiocytic vasculitis. Serial sections are sometimes necessary [70, 71]. The classic histologic features of more advanced uncomplicated LS are hyperkeratosis, epidermal atrophy with flattening of the rete ridges, vacuolar interface changes, loss of elastic fibers, and hyalinization of the lamina propria with an underlying lymphocytic infiltrate, but prominent acanthosis may be a feature particularly in vulvar LS. In a study of 121 cases of vulvar LS, changes in lichen simplex chronicus or spongiotic dermatitis, dermal eosinophils, and a frequent absence of atrophy have been documented [72]. Those vulvar LS cases presenting with eosinophilic spongiosis, marked lymphocyte exocytosis, dermal eosinophils, and excoriations showed a poor symptomatic response to treatment. The cause might be a superimposed allergic contact dermatitis. Patch testing is recommended for these individuals.

The pathology for LS is far from being always conclusive. Thus, for the final diagnosis, the clinicopathologic correlation is pivotal [11].

\section{Treatment}

The various treatment options for anogenital LS are summarized in Table 2. 
Table 2 Treatment of anogenital lichen sclerosus

Minimize irritants, soap substitution, avoidance of urinary contact

Moisturization with emollients

Treatment of infections

Ultrapotent or potent topical corticosteroid once daily at night for 4 weeks, then on alternate nights for 4 weeks, and then twice weekly for a further 4 weeks. Continued suppressive therapy according to the ongoing inflammatory activity

In corticosteroid-resistant cases, consider circumcision in men, application of topical calcineurin inhibitors, topical retinoids in hyperkeratotic lesions, systemic retinoids, or photodynamic therapy

Surgery for intraepithelial neoplasia or carcinoma

Long-term surveillance

\subsection{Emollients}

In a prospective open-label trial, 34 women were treated with topical corticosteroid cream once daily for 1 month. Seventy-one percent became symptom free and $29 \%$ experienced a partial response. Maintenance therapy consisted of an emollient alone. Seventy percent of the women could maintain initial treatment response after a median follow-up of 58 months with cold cream alone [73]. After induction of remission with topical corticosteroids in women with vulvar LS, Cattaneo et al. [74] also observed a good symptomatic control of the disease with a maintenance therapy with an emollient cream alone during the follow-up of 24 weeks.

\subsection{Topical Corticosteroids}

Most patients with LS will respond to topical corticosteroids with relief of symptoms and clinical and histologic improvement. When patients with LS do not respond to topical corticosteroids of an adequate potency and a sufficient duration, diagnosis should be doubted and reappraised, and contact allergy to a constituent of the cream, secondary infections, or malignant evolution should be excluded.

For lack of sufficient long-term studies there are still concerns about the long-term safety of topical corticosteroids. Feared adverse effects of long-term, topical corticosteroid maintenance treatment are atrophy, striae formation, rebound reactions, fungal infections, reactivation of human papilloma virus (HPV) and herpes simplex virus infection, or systemic absorption.

\subsubsection{Female Anogenital LS}

Since the first published small study showing the effectiveness of ultrapotent topical corticosteroids in the treatment of adult vulvar LS [72], several authors have confirmed these positive results [53, 55, 75-78]. Topical ultrapotent corticosteroids gave improvement of symptoms in nearly all patients, complete relief of symptoms in about $70 \%$, and complete remission of skin changes in one-fifth of women with anogenital LS [54, 55]. Thirteen women with vulvar LS treated with clobetasol propionate $0.05 \%$ cream twice daily for 12 weeks showed a significant reduction in epidermal atrophy, hyperkeratosis, epidermal basal cell liquefaction, inflammatory infiltrate, and hyalinization of dermal collagen after treatment. In four of the biopsies, no specific features of LS remained after 12 weeks of treatment [75]. There are no randomized controlled trials providing evidence on how often, how long, and in which potency the corticosteroids are to be applied. However, the recent British Association of Dermatologists guidelines advocate their use and propose a detailed regimen [5]. They recommend for a newly diagnosed case to apply clobetasol propionate $0.05 \%$ ointment once daily at night for 4 weeks, then on alternate nights for 4 weeks, and then twice weekly for a further 4 weeks. If symptoms should recur with reduced frequency the patient should use the treatment more often until symptoms resolve. An ointment formulation is usually better tolerated than a cream base.

Long-term follow-up in 83 women (with a median follow-up time of 4.7 years) confirmed a high rate of relapses of $84 \%$ at 4 years [79], but even with long-term, ultrapotent, topical corticosteroid maintenance treatment, tolerance in this cohort was excellent. Surprisingly, no atrophic effects were observed.

Several studies showed that less potent topical corticosteroids such as mometasone furoate or triamcinolone are also effective to treat vulvar LS [80, 81]. Cattaneo et al. [80] treated 31 women with biopsy-proven vulvar LS with a regimen of $0.1 \%$ mometasone furoate cream application once daily for 4 weeks and then twice weekly for 8 weeks. After 12 weeks of treatment, all women had a significant improvement in the gross aspects of the disease and a very dramatic decrease in symptoms, with nearly all the subjects having complete symptomatic remission. No adverse effects were observed. The use of a less potent topical corticosteroid could be safer in particular for the long-term maintenance treatment of LS. In order to minimize corticosteroid exposure, it is the successful practice of many clinics to lower the potency and frequency of applied corticosteroids once remission has occurred and maintenance therapy is required [76, 82].

In the treatment of childhood vulvar LS, an excellent response to a potent topical corticosteroid (betamethasone dipropionate $0.05 \%$ ) without serious adverse events was first described in a small case series in 1997 [83]. Other authors confirmed the results in prepubertal girls treated 
with ultrapotent topical corticosteroids likewise without having significant adverse effects [7, 84, 85]. Cooper et al. [55] performed a larger study including 74 girls with vulvar LS treated with potent or superpotent topical corticosteroids. Seventy-two percent became symptom free and $25 \%$ experienced subjective improvement, $22 \%$ showed complete resolution of clinical signs, and $67 \%$ showed partial resolution of clinical signs. A long-term follow-up of childhood LS in 15 girls with a mean follow-up of 4.7 years showed the best therapeutic response with an early aggressive treatment, a high recurrence rate of $60 \%$ after 1 year from the first clearing, and the need for maintenance therapy [86].

\subsubsection{Male Genital LS}

Clobetasol dipropionate $0.05 \%$ cream applied for 2-16 weeks improved itching, burning, pain, dyspareunia, phimosis, and dysuria and reduced all histologic features in 22 men with penile LS. Twenty-seven percent required additional circumcision [87]. Also, in another series the majority of 66 men responded to ultrapotent topical corticosteroids as first-line therapy. Twelve percent required circumcision [88]. In the most recent case series, treatment with topical clobetasol propionate was successful in $59 \%$ of 185 men. Forty-one percent failed topical corticosteroid treatment and were subsequently circumcised [33].

In boys with genital LS, topical medium-potency corticosteroids resulted in improvement in clinically and histologically early and intermediate stages of LS, but were ineffective in late stages with established scarring [89, 90]. There are several studies concerning the efficacy of topical corticosteroids in the treatment of phimosis [91-94]. As we know, about $40 \%$ of phimoses in boys are proven histologically to be LS [69]. In an open-label trial including 54 boys with phimosis, clobetasol propionate cream was an effective treatment in $70 \%$ [91]. A prospective, randomized, double-blind, placebo-controlled study in 30 boys with phimosis confirmed a high efficiency of topical clobetasol propionate ointment [92]. Yang et al. [93] showed in a prospective randomized study with 70 boys with phimosis that both moderately potent topical corticosteroids and ultrapotent topical corticosteroids are equally effective in treating phimosis with a response rate of $77 \%$ and $81 \%$, respectively. In 462 boys with phimosis, of whom 12 had LS, the overall response rate after 6 weeks of topical corticosteroids was $86 \%$ [94]. In the subgroup with LS the response rate was $67 \%$. The treatment success was maintained after a median follow-up of 22 months. This study shows that topical corticosteroids are an effective treatment in boys not only for LS, but also for phimosis of other causes.

\subsubsection{Extragenital LS}

Although regularly used in this setting, there are no published randomized controlled trials or case series reporting the use of topical corticosteroids for extragenital LS.

\subsection{Topical Calcineurin Inhibitors}

The topical calcineurin inhibitors (TCIs) pimecrolimus and tacrolimus have a significant anti-inflammatory activity, immunomodulatory effects, and a low systemic immunosuppressive potential. Several reports advocate the use of TCIs in the treatment of anogenital LS as safe and effective and emphasize the lack of atrophogenicity as an advantage over topical corticosteroids. However, atrophy in LS as an adverse effect of treatment with topical corticosteroids has, so far, not clearly been documented. The question of atrophogenicity is difficult to answer as atrophy is part of the LS process itself.

Other authors have vehement objections to applying TCIs in a disease with an intrinsic malignant potential and fear that TCIs in LS will increase the risk of malignant progression [31, 95]. The US FDA collated worldwide reports and found 19 malignancy-related adverse events related to topical tacrolimus and 10 cases related to topical pimecrolimus [155]. Three of these were observed in genital LS treated with TCIs, one penile SCC in a 57-yearold man with genital LS treated with tacrolimus, one vulvar SCC in a 75-year-old woman with genital LS treated with tacrolimus, and one low-grade SCC in a 71-year-old woman treated with pimecrolimus. In 2007, Fischer and Bradford [96] reported on a 73-year-old woman with a 10-year history of hypertrophic LS and genital psoriasis who presented with intractable superimposed inflammatory vulvitis. She was treated with topical pimecrolimus $1 \%$ cream on the assumption that she was either allergic to or intolerant of topical corticosteroids. One month after commencing therapy, she suddenly developed a rapidly growing vulvar tumor. This was excised and proved to be a well differentiated SCC. In the UK, advice has been issued that topical tacrolimus and pimecrolimus should not be applied to malignant or to potentially malignant skin lesions and that treatment should be short term [97].

Finally, it should be kept in mind that TCIs are considerably more expensive than topical corticosteroids. This is particularly significant in a disease with a usually chronic lifelong course.

The role of TCIs in the treatment of inflammatory mucosal disorders [98], and in particular of LS, has been recently reviewed [99]. The use of TCIs in LS is off label. The patient has to be informed about this circumstance prior to the prescription. 


\subsubsection{Pimecrolimus}

In 2004, the first case reports of LS treated with a twicedaily application of pimecrolimus cream $1 \%$ in children [100, 101] and adults [102] were published, each with considerable improvement of clinical signs and symptoms within 6 weeks of treatment and almost complete remission within 12-16 weeks of treatment.

A pilot study in 2007 evaluated the efficacy and safety of pimecrolimus cream $1 \%$ applied twice daily for up to 6 months for severe vulvar LS [103]. Complete remission with relief from itchiness, pain, and inflammation was achieved in $35 \%(9 / 26)$ after 2 months and in $42 \%(11 / 26)$ after 6 months. After 2 months of treatment, a 3.5-fold increase in type I and a 7.5-fold increase in type III collagen synthesis of the affected areas could be observed. There were no systemic adverse reactions. Mild local burning and itching during the first 3-14 days were reported by $50 \%$ of the women. Three patients had withdrawn from the study during the first week because of pruritus and/or no satisfactory response. Blood concentrations of pimecrolimus checked in 10/26 patients were undetectable in all cases.

At the same time another prospective study evaluating the efficacy, tolerability, and safety of pimecrolimus cream $1 \%$ in 16 postmenopausal women with histologically proven vulvar LS was published [104]. After 3 months of treatment, complete remission was achieved in $69 \%$ and partial remission in $25 \%$ of the patients and biopsies in eight patients showed that typical histologic features of LS had disappeared. The only adverse effect was a mild to moderate burning sensation at the application site during the first week of treatment in one-third of women.

The effects of pimecrolimus on p53, Bcl-2, and Ki-67 expression in vulvar LS have been investigated in 25 women with active LS [105]. After 2 months of treatment with twice-daily pimecrolimus cream $1 \%$, complete remission was achieved in $76 \%$ and partial remission in $4 \%$. Posttreatment biopsies revealed decreased p53 staining and an increased number and staining intensity of Bcl-2-positive basal keratinocytes. Whether the decrease in p53 and increase in Bcl-2 expression will provide protection from malignant progression warrants long-term follow-up. The clinical remission correlated with a marked reduction in lymphocytes of the vulvar skin, mainly CD3-negative T lymphocytes and CD8-negative cytotoxic T lymphocytes. Moreover, the number of CD57-negative natural killer cells was decreased. Pimecrolimus did not affect B cells [106].

The first and only comparative study is a double-blind, randomized controlled trial comparing the safety and efficacy of clobetasol with pimecrolimus in the treatment of vulvar LS [107]. Seventeen women in the pimecrolimus group and 19 women in the clobetasol group all had biopsy-proven vulvar LS. Pimecrolimus cream was applied twice daily and clobetasol cream once daily for 12 weeks. At the end of the treatment period, clobetasol was found to be superior to pimecrolimus in improving histologically controlled inflammation. However, this fact was not clinically relevant since there was no statistically significant difference in subjective improvement of pruritus, burning, and pain or objective clinical assessment by the investigator between the two treatment groups.

Kim et al. [108] recently added an oral case of LS in a 7-year-old girl successfully treated with pimecrolimus cream $1 \%$ twice daily for 8 weeks. After unsatisfactory treatment with ultrapotent topical corticosteroids, the lesion improved within 4 weeks of treatment with pimecrolimus and disappeared after 12 weeks.

\subsubsection{Tacrolimus}

The first case reports of LS treated with tacrolimus ointment $0.1 \%$ in three women, in three prepubertal girls, and in two men have been published in 2003 and 2005 [109-112]. Complete remission was achieved in all patients after 6 weeks to 10 months of treatment.

In the first pilot study, 16 women with histologically proven vulvar LS were treated with tacrolimus ointment $0.1 \%$ twice daily [113]. By the end of 3 months, $12.5 \%$ achieved a complete response, and this was maintained at 12 months. Fifty percent experienced partial improvement and wished to continue on tacrolimus. $37.5 \%$ were nonresponders. There was no influence of age, menopausal status, or duration of symptoms on treatment response. Onethird reported a transient, mild, local burning sensation.

A second pilot study reported 11 women with vulvar LS achieving complete remission in $36 \%$ and partial remission in $55 \%$ after 3 months of treatment with tacrolimus ointment $0.1 \%$ [114].

A multicenter, phase II trial evaluated the safety and efficacy of tacrolimus ointment $0.1 \%$ for the treatment of LS [115]. Eighty-four patients ( 49 women, 32 men, and 3 girls) aged between 5 and 85 years with long-standing, active LS (79 with anogenital and 5 with extragenital localization) were treated with tacrolimus ointment $0.1 \%$ twice daily for 16 weeks. If deemed clinically beneficial, treatment was continued until week 24 . Complete remission was achieved in $43 \%$ and partial remission in $34 \%$ of patients. Maximal effects occurred between weeks 10 and 24 of therapy. Transient burning and itching during the first days of treatment were the most common adverse events, leading two patients to intermittently stop tacrolimus application and one patient to withdraw from the study. Infections such as genital herpes and vulvovaginal candidiasis each occurred in $2 \%$ of patients. No malignancy was observed during an 18-month follow-up period. 
Sotiriou et al. [116] treated ten postmenopausal women with recalcitrant vulvar LS with tacrolimus ointment $0.1 \%$ twice daily for 8 weeks. Mild local burning during the first days of treatment occurred in four patients. Reduction in pruritus, burning, and pain occurred within the first 2 weeks of treatment in all patients. Mean values in the visual analog scale decreased from 2.55 at baseline to 0.95 at week 8. Analysis of objective scores, however, showed only a minor influence on hyperkeratosis, atrophy, sclerosis, and depigmentation, probably explained by the short duration of treatment of only 8 weeks.

Matsumoto et al. [117] reported on a 5-year-old girl with vulvar LS unresponsive to mild topical corticosteroids. She was treated successfully with tacrolimus ointment $0.03 \%$ once daily with complete remission after 14 weeks without any adverse effects.

\subsection{Topical Testosterone}

The treatment of LS with topical testosterone has been abandoned because of ineffectiveness [74, 118, 119], due to the superiority of ultrapotent topical corticosteroids [120, 121], systemic absorption, and virilizing effects in female patients [122-125].

\subsection{Topical and Systemic Retinoids}

Although topical and systemic retinoids have been shown to be useful, they did not become widely accepted in the treatment of vulvar LS, probably due to their well known adverse effects and severe teratogenicity and the need for long-term treatment in a usually chronically relapsing disease.

Several case series showed definitely respectable results in the treatment of vulvar LS with systemic and topical retinoids [126-128]. Topical $0.025 \%$ tretinoin once a day, 5 days per week, for 1 year improved symptoms, clinical appearance, and histopathologic features in 22 women treated for vulval LS [129]. Cutaneous irritation was mild and transient.

Six of eight women treated with oral etretinate with an initial dose of $1 \mathrm{mg} / \mathrm{kg} /$ day for vulval LS showed improvement in symptoms and clinical signs, and in four of five women improvement was reflected also in histopathology [125]. Romppanen et al. [126] also observed excellent results with systemic etretinate in the treatment of 19 women with vulvar LS treated previously unsuccessfully with topical estrogen and corticosteroids. In over $90 \%$ of women, symptoms, signs, and histopathologic features improved significantly. Finally, the good results from treatment with oral retinoids in women with severe vulvar LS have been confirmed in a double-blind, placebo-controlled study
[128]. Acitretin 20-30 mg/day for 16 weeks led to treatment response in two-thirds of women. All patients treated with systemic retinoids experienced the typical retinoid adverse effects in various degrees.

Only one published study deals with retinoids as a treatment in male genital LS [130]. It is a randomized, double-blind, placebo-controlled study in which 52 male patients with severe, long-standing LS resistant to topical treatment with ultrapotent corticosteroids, were randomized to receive acitretin $35 \mathrm{mg} /$ day or placebo for 20 consecutive weeks. Complete response was achieved by $36.4 \%$ of the acitretin group versus $6.3 \%$ of the controls, while $36.4 \%$ versus $12.5 \%$ achieved partial resolution, respectively. Mean time to partial response was 17 weeks and to complete response 20 weeks. The well known, expected adverse effects of retinoids were observed in a high percentage of patients.

\subsection{Surgery}

In women with anogenital LS, surgery should be limited to patients with associated vulvar intraepithelial neoplasia or malignancy or to correct scarring interfering with normal function [54]. Introital stenosis may lead to difficulties with micturition or sexual intercourse and may require introital widening. Surgery should not be performed until the disease activity has ceased.

In penile LS, surgery has a more important role. In male patients who have failed medical management or who present with advanced disease with structural changes due to scarring, circumcision is indicated and has a success rate of 76-100\% [33, 64, 131]. Removal of the foreskin alters the local environment, which plays an important role in the etiogenesis of penile LS. LS may koebnerize in the circumcision scar. Meatal stenosis can be treated with ventral meatotomy or dorsal V-meatoplasty [66]. In cases of urethral stenosis, urethroplasty with buccal and/or bladder mucosa grafts may be necessary [51].

\subsection{Phototherapy and Photodynamic Therapy}

\subsubsection{Psoralen plus UVA (PUVA) Cream Photochemotherapy for Genital LS}

Reichrath et al. [132] tretated five women with vulvar LS with topical psoralen plus UVA (PUVA) therapy using 8-methoxypsoralen (8-MOP)-containing cream. The mean number of treatments administered was 25.6 (range 5-104), and the mean cumulative UVA dose was $44.2 \mathrm{~J} / \mathrm{cm}^{2}$ (range 4.0-180). Two patients showed marked improvement with complete reduction in pruritus and an increase in tenderness, two showed improvement, and one had stable disease. 


\subsubsection{Bath and Peroral PUVA Photochemotherapy for Extragenital LS}

In 1997, the first case of extragenital LS successfully treated with PUVA bath photochemotherapy over a period of 6 weeks was described [133]. The cumulative UVA dose was $31.7 \mathrm{~J} / \mathrm{cm}^{2}$. The single UVA dose ranged from 0.3 to $2.3 \mathrm{~J} / \mathrm{cm}^{2}$. After 24 treatments, the skin lesions were almost completely cleared and pruritus was diminished.

A 10-year-old girl with LS on the trunk was treated with systemic PUVA with peroral methoxsalen $30 \mathrm{mg}$ $(0.75 \mathrm{mg} / \mathrm{kg})$ and a total UVA dose of $61 \mathrm{~J} / \mathrm{cm}^{2}$ [134]. After 3 months of oral PUVA there were no new lesions and previous ones resolved completely or with residual hyperpigmentation.

Another woman with extensive extragenital LS showed great clinical and subjective improvement with $0.1 \%$ tacrolimus ointment and PUVA (single dose of $1-4.6 \mathrm{~J} / \mathrm{cm}^{2}$ and total cumulative dose of $79 \mathrm{~J} / \mathrm{cm}^{2}$ ) [135].

\subsubsection{UVA1}

Seven women with severe genital LS uncontrolled by ultrapotent topical corticosteroids were treated with UVA1 [136]. They received 15-65 UVA1 exposures to the perineum. The maximum single dose varied from 20 to $140 \mathrm{~J} /$ $\mathrm{cm}^{2}$, the total dose from 190 to $2200 \mathrm{~J} / \mathrm{cm}^{2}$. Two women with coexistent extragenital LS also received whole-body UVA1 treatment. Three achieved moderate and two achieved minimal improvement of the genital LS. Two of these five responders relapsed. Response of extragenital lesions tended to be greater than that of genital lesions.

In an open-label study, Kreuter et al. [137] presented the improvement of extragenital LS in ten patients treated by UVA1 phototherapy (four sessions per week for 10 weeks, $20 \mathrm{~J} / \mathrm{cm}^{2}$ low-dose UVA1 per session, $800 \mathrm{~J} / \mathrm{cm}^{2}$ cumulative dose). An obvious softening of sclerotic plaques was observed after the tenth session in most patients, whereas repigmentation of former porcelain-like polygonal patches was detected after the 20th irradiation in all patients. Increased corium thickness was decreased to the normal range and there was also a highly significant increase of dermal density after UVA1 irradiation.

\subsubsection{UVB}

An individual case of extragenital LS treated successfully with narrow-band UVB has been reported [138].

\subsubsection{Photodynamic Therapy}

Photodynamic therapy (PDT) seems to be a reasonably effective alternative therapeutic modality to treat LS resistant to conventional treatment, as shown by several case series [139-142]. The first results were published in 1999 [139] and are consistent with the results obtained by the subsequent studies [140-142]. Twelve women with genital LS underwent one to three cycles of 5-ALA PDT (5-aminolevulinic acid and argon dye laser). Ten of the twelve women experienced good symptomatic control of their disease after treatment, with alleviation of pruritus and pain sustained for 6 months [139]. Altogether, the studies showed no substantial influence on the objective clinical and histopathologic scores. Common adverse effects were pain and a stinging and burning sensation during treatment. Local erythema occurred up to 1 week after therapy. The most recent study included 100 women with genital LS treated with PDT [143]. Partial or even full remission of subjective symptoms and objective clinical signs could be observed. After six courses of PDT the immunohistochemical staining in vulvar LS showed increasing microvessel density and decreasing lymphocytic infiltration [143, 144].

\section{Prognosis}

In a descriptive cohort study with a mean follow-up of 66 months, 327 patients (74 girls and 253 women) with vulvar LS have been treated with topical corticosteroids [54]. Clinical signs improved in nearly all patients, but only $22 \%$ of the girls and $23 \%$ of the women showed complete resolution of clinical signs with return to normal skin texture and color [54]. The concept that prepubertal LS resolves at puberty appears not to be true in the majority of patients. Seventy-five percent of girls who develop LS prior to puberty will continue to require maintenance therapy after menarche $[52,53]$.

There is a significant risk for women with vulvar LS to develop scarring with loss of vulvar architecture and normal function. Cooper et al. [55] showed in their study of 327 women that a delay in diagnosis of 2 years or less was associated with less scarring at diagnosis. In a second longterm study (mean follow-up 6.2 years), the authors compared the data of 84 fully compliant women with 45 partly compliant women with vulvar LS [82]. Ninety-eight percent of the fully compliant patients achieved complete symptom control, including ability to resume sexual activity without pain. None had disease progression. In partially compliant patients, only $75 \%$ achieved complete symptom control and $35 \%$ experienced progression of disease with scarring and fusion.

A survey of men with genital LS with a mean length of follow-up of 15.2 months showed that $59 \%$ of 185 men treated medically with topical clobetasol propionate together with adjunctive measures, such as strict avoidance of 
contact with soap and urine, and moisturization, became symptom free [33]. If maximal conventional medical management had failed, with persistent dyspareunia or rash, penile carcinoma in situ, and urologic dysfunction, then circumcision was recommended. In $76 \%$ of those cases circumcision was curative; $24 \%$ of the total circumcised cases required on-going medical therapy despite circumcision [33].

A rare complication of genital LS is SCC (Fig. 17). In the literature the incidence of SCC in vulvar LS is reported to be between 0.3 and $4.9 \%$ [1, 10, 55, 145, 146]. In vulvar LS, advanced age and clinical evidence of squamous hyperplasia are independent risk factors for developing vulvar carcinoma as shown in a retrospective case-control study by Jones et al. [147] If histologic changes of LS adjacent to vulvar SCCs are searched, LS has been found in $33 \%$ of 1287 patients with vulvar SCC (range 7-85\%) [145]. Chiesa-Vottero et al. [148] examined 44 thin $(\leq 5-$ $\mathrm{mm}$ tumor thickness), invasive vulvar SCCs. LS was present in $32 \%$. In patients with adjacent LS, all SCCs were of the keratinizing type. In the warty- and basaloidtype SCC, LS was not present. In the study by Cooper et al. [55], 6 of 327 women with vulvar LS developed SCCs. The delay in diagnosis of vulvar LS was greater in the six women with SCC than in those women with no malignancy (15.3 vs. 4.4 years). However, because of the small numbers of SCCs this difference was not statistically significant. In the long-term follow-up study by Bradford and Fischer [82], 5 of 45 partly compliant women developed SCC, whereas none of the 84 fully compliant women developed malignancy.

In a review of 86 biopsies of male genital LS, six penile SCCs (7 \%), one erythroplasia of Queyrat, and one

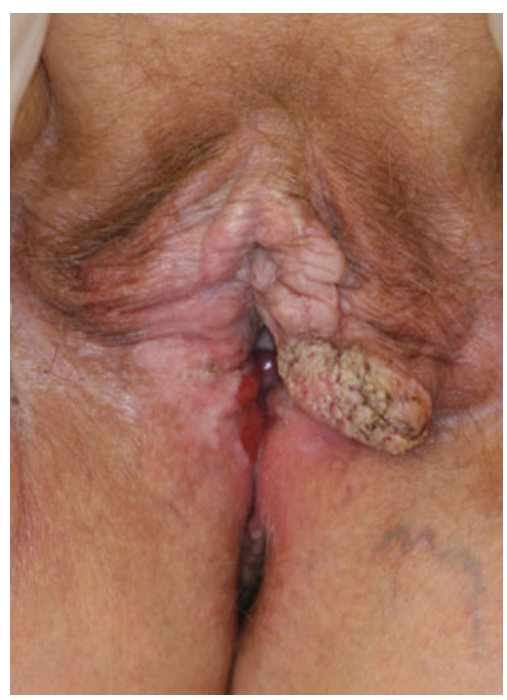

Fig. 17 An 89-year-old woman with long-standing anogenital lichen sclerosus. She developed a nodular lesion firm to palpation on the left side of the vulva. Biopsy confirmed an invasive carcinoma verrucous carcinoma were found, corresponding to a malignancy rate of $9.3 \%(8 / 86)$ [149, 150]. The average lag time from onset of LS to the emergence of malignancy was 18 years (range 10-34 years). In five of those eight patients HPV 16 was detected [145]. Barbagli et al. [151] reexamined the histology of 130 men with genital LS. Eleven $(8.5 \%)$ showed premalignant or malignant histopathologic features, including seven SCCs, two verrucous carcinomas, one erythroplasia of Queyrat, and one SCC associated with verrucous carcinoma. Retrospective analyses of patients with penile carcinoma show LS in a high number of cases. In 2001, Powell et al. [152] reviewed 20 penile SCCs and found histologic features and/or a clinical history of genital LS in 11 (55\%). Perceau et al. [153] reviewed 18 cases of penile SCCs and found a histology of LS in eight of them (44\%). All eight SCCs associated with LS were negative for oncogenic HPV types. Velazquez and Cubilla [154] examined 207 penectomy and circumcision specimens with SCCs and giant condylomas and among them histologically identified 68 cases of LS (33\%).

It is not assured if medical treatment of LS can prevent the evolution to malignancy. However, the existing longterm follow-up studies suggest that early diagnosis and early treatment with good compliance might not only lower rates of malignancies but also prevent scarring [54, 81].

\section{Conclusion}

The etiology of LS is still unknown. There is evidence supporting an autoimmune etiology in genetically predisposed patients. Patients with LS and their relatives have more frequently occurring, autoimmune-related disorders and autoimmune antibodies than controls. Thyroid disease, alopecia areata, vitiligo, and pernicious anemia should be considered in a patient diagnosed with LS. The detection of autoantibodies to ECM1 and to BMZ components suggests that autoimmunity to these components might contribute to the pathogenesis of LS. However, those antibodies rather then being causative and involved in the initiation, might be a result of damage to the $\mathrm{BMZ}$, and contribute to the progression of the disease. An infectious etiology has been proposed, but could never be definitively confirmed. The role of B. burgdorferi is still unclear. Hormonal influences do not seem to play a major role.

LS may lead to scarring and destruction of the normal genital architecture. In a high proportion of affected women and men, LS causes sexual dysfunction.

The diagnosis of LS is usually clinical. In clinically unclear cases, a histologic examination is required. Although classic histologic findings will confirm the diagnosis, a nonspecific histology does not rule out LS. The clinicopathologic correlation is pivotal. Patients under 
follow-up will need a biopsy in the case of a persistent area of hyperkeratosis, erosion or erythema, or a warty or nodular lesion, in the case of any area resistant to adequate treatment, in the case of unclear pigmentation, and if a second-line therapy is going to be introduced.

Topical corticosteroids are highly effective, and remain the first-line treatment for LS. They often give relief of symptoms in the first few days of treatment. Emollients are recommended as a supportive treatment. TCIs are an alternative treatment option for patients who have failed therapy with ultrapotent corticosteroids, or who have a contraindication for the use of corticosteroids. However, there are still serious concerns for an increased risk of malignant transformation of genital LS due to local immunosuppression by long-term use of TCIs in a disease with an intrinsic potential for malignant evolution [31, 95]. With TCIs, prolonged therapy of up to 24 weeks may be necessary to obtain optimal response.

Systemic retinoids have been used in the past with considerable success in severe vulvar LS, but in women of childbearing age the teratogenic risk limits their use.

Surgery should be limited to patients with associated malignancy or to patients who need correction of functionally restricting, scarring processes.

Phototherapy and PDT are possible third-line therapies in cases resistant to the aforementioned treatments.

Genital LS is associated with scarring and an increased risk for vulvar and penile SCC. Long-term follow-up and ongoing suppressive treatment are mandatory.

Acknowledgments No sources of funding were received to prepare this article. The authors have no conflicts of interest that are directly relevant to the content of this article.

Open Access This article is distributed under the terms of the Creative Commons Attribution Noncommercial License which permits any noncommercial use, distribution, and reproduction in any medium, provided the original author(s) and the source are credited.

\section{References}

1. Wallace HJ. Lichen sclerosus et atrophicus. Trans St Johns Hosp Dermatol Soc. 1971;57:9-30.

2. Brown AR, Dunlap CL, Bussard DA, et al. Lichen sclerosus et atrophicus of the oral cavity: report of two cases. Oral Surg Oral Med Oral Pathol Oral Radiol Endod. 1997;84:165-70.

3. Jensen T, Worsaae N, Melgaard B. Oral lichen sclerosus et atrophicus: a case report. Oral Surg Oral Med Oral Pathol Oral Radiol Endod. 2002;94:702-6.

4. Azevedo RS, Romañach MJ, de Almeida OP, et al. Lichen sclerosus of the oral mucosa: clinicopathological features of six cases. Int J Oral Maxillofac Surg. 2009;38:855-60.

5. Neill SM, Lewis FM, Tatnall FM, et al. British Association of Dermatologists' guidelines for the management of lichen sclerosus 2010. Br J Dermatol. 2010;163:672-82.
6. Goldstein AT, Marinoff SC, Christopher K, et al. Prevalence of vulvar lichen sclerosus in a general gynecology practice. J Reprod Med. 2005;50:477-80.

7. Powell J, Wojnarowska F. Childhood vulvar lichen sclerosus: an increasingly common problem. J Am Acad Dermatol. 2001; 44:803-6.

8. Kizer WS, Prarie T, Morey AF. Balanitis xerotica obliterans: epidemiologic distribution in an equal access health care system. South Med J. 2003;96:9-11.

9. Nelson DM, Peterson AC. Lichen sclerosus: epidemiological distribution in an equal access health care system. J Urol. 2011;185:522-5.

10. Meyrick Thomas RH, Ridley CM, McGibbon DH, et al. Lichen sclerosus et atrophicus and autoimmunity: a study of 350 women. Br J Dermatol. 1988;118:41-6.

11. Murphy R. Lichen sclerosus. Dermatol Clin. 2010;28:707-15.

12. Cooper SM, Ali I, Baldo M, et al. The association of lichen sclerosus and erosive lichen planus of the vulva with autoimmune disease: a case-control study. Arch Dermatol. 2008;144:1432-5.

13. Birenbaum DL, Young RC. High prevalence of thyroid disease in patients with lichen sclerosus. J Reprod Med. 2007;52:28-30.

14. Leese GP, Flynn RV, Jung RT, et al. Increasing prevalence and incidence of thyroid disease in Tayside, Scotland: the Thyroid Epidemiology Audit and Research Study (TEARS). Clin Endocrinol (Oxf). 2008;68:311-6.

15. Powell J, Wojnarowska F, Winsey $\mathrm{S}$, et al. Lichen sclerosus premenarche: autoimmunity and immunogenetics. Br J Dermatol. 2000;142:481-4.

16. Lipscombe TK, Wayte J, Wojnarowska F, et al. A study of clinical and aetiological factors and possible associations of lichen sclerosus in males. Australas J Dermatol. 1997;38:132-6.

17. Azurdia RM, Luzzi GA, Byren I, et al. Lichen sclerosus in adult men: a study of HLA associations and susceptibility to autoimmune disease. Br J Dermatol. 1999;140:79-83.

18. Bjekić M, Šipetić S, Marinković J. Risk factors for genital lichen sclerosus in men. Br J Dermatol. 2011;164:325-9.

19. Oyama N, Chan I, Neill SM, et al. Autoantibodies to extracellular matrix protein 1 in lichen sclerosus. Lancet. 2003;362: $118-23$.

20. Edmonds EV, Oyama N, Chan I, et al. Extracellular matrix protein 1 autoantibodies in male genital lichen sclerosus. Br J Dermatol. 2011;165:218-9.

21. Chan I. The role of extracellular matrix protein 1 in human skin. Clin Exp Dermatol. 2004;29:52-6.

22. Howard A, Dean D, Cooper S, et al. Circulating basement membrane zone antibodies are found in lichen sclerosus of the vulva. Australas J Dermatol. 2004;45:12-5.

23. Baldo M, Bailey A, Bhogal B, et al. T cells reactive with the NC16A domain of BP180 are present in vulval lichen sclerosus and lichen planus. J Eur Acad Dermatol Venereol. 2010;24: 186-90.

24. Baldo M, Bhogal B, Groves RW, et al. Childhood vulval lichen sclerosus: autoimmunity to the basement membrane zone protein BP180 and its relationship to autoimmunity. Clin Exp Dermatol. 2010;35:543-5.

25. Gambichler T, Höxtermann S, Skrygan M, et al. Occurrence of circulating anti-bullous pemphigoid antibodies in patients with lichen sclerosus. J Eur Acad Dermatol Venereol. 2011;25: 369-70.

26. Sherman V, McPherson T, Baldo M, et al. The high rate of familial lichen sclerosus suggests a genetic contribution: an observational cohort study. J Eur Acad Dermatol Venereol. 2010;24:1031-4.

27. Marren P, Yell J, Charnock FM, et al. The association between lichen sclerosus and antigens of the HLA system. Br J Dermatol. 1995;132:197-203. 
28. Sentürk N, Aydin F, Birinci A, et al. Coexistence of HLA-B*08 and HLA-B*18 in four siblings with lichen sclerosus. Dermatology. 2004;208:64-6.

29. Aslanian FM, Marques MT, Matos HJ, et al. HLA markers in familial lichen sclerosus. J Dtsch Dermatol Ges. 2006;4:842-7.

30. Gao XH, Barnardo MC, Winsey S, et al. The association between HLA DR, DQ antigens, and vulval lichen sclerosus in the UK: HLA DRB112 and its associated DRB112/DQB10301/ 04/09/010 haplotype confers susceptibility to vulval lichen sclerosus, and HLA DRB10301/04 and its associated DRB10301/04/DQB10201/02/03 haplotype protects from vulval lichen sclerosus. J Invest Dermatol. 2005;125:895-9.

31. Bunker CB. Male genital lichen sclerosus and tacrolimus. Br J Dermatol. 2007;157:1079-80.

32. Bunker CB, Edmonds E, Hawkins D, et al. Re: Lichen sclerosus: review of the literature and current recommendations for management: J. M. Pugliese, A. F. Morey and A. C. Peterson J Urol 2007; 178: 2268-76. J Urol. 2009;181:1502-3.

33. Edmonds EV, Hunt S, Hawkins D, et al. Clinical parameters in male genital lichen sclerosus: a case series of 329 patients. J Eur Acad Dermatol Venereol. Epub 2011 Jun 27.

34. Edmonds EC, Bunker CB. Nuclear magnetic resonance spectroscopy of urine in male genital lichen sclerosus. Br J Dermatol. 2010;163:1355-6.

35. Edmonds E, Mavin S, Francis N, et al. Borrelia burgdorferi is not associated with genital lichen sclerosus in men. Br J Dermatol. 2009;160:459-60.

36. Aberer E, Stanek G. Histological evidence for spirochetal origin of morphea and lichen sclerosus et atrophicans. Am J Dermatopathol. 1987;9:374-9.

37. Aberer E, Kollegger H, Kristoferitsch W, et al. Neuroborreliosis in morphea and lichen sclerosus et atrophicus. J Am Acad Dermatol. 1988;19:820-5.

38. Schempp C, Bocklage H, Lange R, et al. Further evidence for Borrelia burgdorferi infection in morphea and lichen sclerosus et atrophicus confirmed by DNA amplification. J Invest Dermatol. 1993;100:717-20.

39. Ranki A, Aavik E, Peterson P, et al. Successful amplification of DNA specific for Finnish Borrelia burgdorferi isolates in erythema chronicum migrans but not in circumscribed scleroderma lesions. J Invest Dermatol. 1994;102:339-45.

40. Fujiwara H, Fujiwara K, Hashimoto K, et al. Detection of Borrelia burgdorferi DNA (B garinii or B afzelii) in morphea and lichen sclerosus et atrophicus tissues of German and Japanese but not of US patients. Arch Dermatol. 1997;133:41-4.

41. Alonso-Llamazares J, Persing DH, Anda P, et al. No evidence for Borrelia burgdorferi infection in lesions of morphea and lichen sclerosus et atrophicus in Spain: a prospective study and literature review. Acta Derm Venereol. 1997;77:299-304.

42. Aberer E, Schmidt BL, Breier F, et al. Amplification of DNA of Borrelia burgdorferi in urine samples of patients with granuloma annulare and lichen sclerosus et atrophicus. Arch Dermatol. 1999;135:210-2.

43. Özkan S, Atabey N, Fetil E, et al. Evidence for Borrelia burgdorferi in morphea and lichen sclerosus. Int $\mathrm{J}$ Dermatol. 2000;39:278-83.

44. Breier F, Khanakah G, Stanek G, et al. Isolation and polymerase chain reaction typing of Borrelia afzelii from a skin lesion in a seronegative patient with generalized ulcerating bullous lichen sclerosus et atrophicus. Br J Dermatol. 2001;144:387-92.

45. Eisendle K, Grabner T, Kutzner H, et al. Possible role of Borrelia burgdorferi sensu lato infection in lichen sclerosus. Arch Dermatol. 2008;144:591-8.

46. Zollinger T, Mertz KD, Schmid M, et al. Borrelia in granuloma annulare, morphea and lichen sclerosus: a PCR-based study and review of the literature. J Cutan Pathol. 2010;37:571-7.
47. Aidé S, Lattario FR, Almeida G, et al. Epstein-Barr virus and human papillomavirus infection in vulvar lichen sclerosus. J Low Genit Tract Dis. 2010;14:319-22.

48. Friedrich EG Jr, Kalra PS. Serum levels of sex hormones in vulvar lichen sclerosus, and the effect of topical testosterone. N Engl J Med. 1984;310:488-91.

49. Clifton MM, Garner IB, Kohler S, et al. Immunohistochemical evaluation of androgen receptors in genital and extragenital lichen sclerosus: evidence for loss of androgen receptors in lesional epidermis. J Am Acad Dermatol. 1999;41:43-6.

50. Günthert AR, Faber M, Knappe G, et al. Early onset vulvar lichen sclerosus in premenopausal women and oral contraceptives. Eur J Obstet Gynecol Reprod Biol. 2008;137:56-60.

51. Depasquale I, Park AJ, Bracka A. The treatment of balanitis xerotica obliterans. BJU Int. 2000;86:459-65.

52. Smith SD, Fischer G. Childhood onset vulvar lichen sclerosus does not resolve at puberty: a prospective case series. Pediatr Dermatol. 2009;26:725-9.

53. Powell J, Wojnarowska F. Childhood vulvar lichen sclerosus: the course after puberty. J Reprod Med. 2002;47:706-9.

54. Funaro D. Lichen sclerosus: a review and practical approach. Dermatol Ther. 2004;17:28-37.

55. Cooper SM, Gao XH, Powell JJ, et al. Does treatment of vulvar lichen sclerosus influence its prognosis? Arch Dermatol. 2004;140:702-6.

56. Lorenz B, Kaufman RH, Kutzner SK. Lichen sclerosus: therapy with clobetasol propionate. J Reprod Med. 1998;43:790-4.

57. Simpkin S, Oakley A. Clinical review of 202 patients with vulval lichen sclerosus: a possible association with psorasis. Australas J Dermatol. 2007;48:28-31.

58. Meyrick Thomas RH, Ridley CM, McGibbon DH, et al. Anogenital lichen sclerosus in women. J R Soc Med. 1996;89:694-8.

59. Schaffer JV, Orlow SJ. Melanocytic proliferations in the setting of vulvar lichen sclerosus: diagnostic considerations. Pediatr Dermatol. 2005;22:276-8.

60. Clark WH, Hood AF, Tucker MA, et al. Atypical melanocytic nevi of the genital type with a discussion of reciprocal parenchymal-stromal interactions in the biology of neoplasia. Hum Pathol. 1998;29(Suppl. 1):S1-24.

61. Carlson JA, Mu XC, Slominski A, et al. Melanocytic proliferations associated with lichen sclerosus. Arch Dermatol. 2002;138:77-87.

62. Dalziel KL. Effect of lichen sclerosus on sexual function and parturition. J Reprod Med. 1995;40:351-4.

63. Burrows LJ, Creasey A, Goldstein AT. The treatment of vulvar lichen sclerosus and female sexual dysfunction. J Sex Med. 2011;8:219-22.

64. Khachemoune A, Guldbakke KK, Ehrsam E. Infantile perineal protrusion. J Am Acad Dermatol. 2006;54:1046-9.

65. Aynaud O, Piron D, Casanova JM. Incidence of preputial lichen sclerosus in adults: histologic study of circumcision specimens. J Am Acad Dermatol. 1999;41:923-6.

66. Pugliese JM, Morey AF, Peterson AC. Lichen sclerosus: review of the literature and current recommendations for management. J Urol. 2007;178:2268-76.

67. Chalmers RJ, Burton PA, Bennett RF, et al. Lichen sclerosus et atrophicus: a common and distinctive cause of phimosis in boys. Arch Dermatol. 1984;120:1025-7.

68. Meuli M, Briner J, Hanimann B, et al. Lichen sclerosus et atrophicus causing phimosis in boys: a prospective study with 5-year followup after complete circumcision. J Urol. 1994;152:987-9.

69. Kiss A, Király L, Kutasy B, et al. High incidence of balanitis xerotica obliterans in boys with phimosis: prospective 10-year study. Pediatr Dermatol. 2005;22:305-8.

70. Regauer S, Liegl B, Reich O. Early vulvar lichen sclerosus: a histopathological challenge. Histopathology. 2005;47:340-7. 
71. Regauer S, Liegl B, Reich H, et al. Vulvar lichen sclerosus: the importance of early clinical and histological diagnosis. Hautarzt. 2004;55:158-64.

72. Carlson JA, Lamb P, Malfetano J, et al. Clinicopathologic comparison of vulvar and extragenital lichen sclerosus: histologic variants, evolving lesions, and etiology of 141 cases. Mod Pathol. 1998;11:844-54.

73. Simonart T, Lahaye M, Simonart JM. Vulvar lichen sclerosus: effect of maintenance treatment with a moisturizer on the course of the disease. Menopause. 2008;15:74-7.

74. Cattaneo A, Carli P, De Marco A, et al. Testosterone maintenance therapy: effects on vulvar lichen sclerosus treated with clobetasol propionate. J Reprod Med. 1996;41:99-102.

75. Dalziel KL, Millard PR, Wojnarowska F. The treatment of vulval lichen sclerosus with a very potent topical steroid (clobetasol propionate 0.05\%) cream. Br J Dermatol. 1991;124: $461-4$.

76. Dalziel KL, Wojnarowska F. Long-term control of vulval lichen sclerosus after treatment with a potent topical steroid cream. J Reprod Med. 1993;38:25-7.

77. Ayhan A, Guven S, Guvendag Guven ES, et al. Topical testosterone versus clobetasol for vulvar lichen sclerosus. Int $\mathbf{J}$ Gynaecol Obstet. 2007;96:117-21.

78. Smith YR, Haefner HK. Vulvar lichen sclerosus, pathophysiology and treatment. Am J Clin Dermatol. 2004;5:105-25.

79. Renaud-Vilmer C, Cavelier-Balloy B, Porcher R, et al. Vulvar lichen sclerosus: effect of long-term topical application of a potent steroid on the course of the disease. Arch Dermatol. 2004;140:709-12.

80. Cattaneo A, De Magnis A, Botti E, et al. Topical mometasone furoate for vulvar lichen sclerosus. J Reprod Med. 2003;48: 444-8.

81. Lefevre C, Hoffstetter S, Meyer S, et al. Management of lichen sclerosus with triamcinolone ointment: effectiveness in reduction of patient symptom scores. J Low Genit Tract Dis. 2011;15:205-9.

82. Bradford J, Fischer G. Long-term management of vulval lichen sclerosus in adult women. Aust $\mathrm{N} \mathrm{Z} \mathrm{J}$ Obstet Gynaecol. 2010;50:148-52.

83. Fischer G, Rogers M. Treatment of childhood vulvar lichen sclerosus with potent topical corticosteroid. Pediatr Dermatol. 1997; 14:235-8.

84. Garzon MC, Paller AS. Ultrapotent topical corticosteroid treatment of childhood genital lichen sclerosus. Arch Dermatol. 1999; 135:525-8.

85. Smith YR, Quint EH. Clobetasol propionate in the treatment of premenarchal vulvar lichen sclerosus. Obstet Gynecol. 2001; 98:588-91.

86. Patrizi A, Gurioli C, Medri M, et al. Childhood lichen sclerosus: a long-term follow-up. Pediatr Dermatol. 2010;27:101-3.

87. Dahlman-Ghozlan K, Hedblad MA, von Krogh G. Penile lichen sclerosus et atrophicus treated with clobetasol dipropionate $0.05 \%$ cream: a retrospective clinical and histopathological study. J Am Acad Dermatol. 1999;40:451-7.

88. Riddell L, Edwards A, Sherrard J. Clinical features of lichen sclerosus in men attending a department of genitourinary medicine. Sex Transm Infect. 2000;76:311-3.

89. Kiss A, Csontai A, Pirót L, et al. The response of balanitis xerotica obliterans to local steroid application compared with placebo in children. J Urol. 2001;165:219-20.

90. Vincent MV, Mackinnon E. The response of clinical balanitis xerotica obliterans to the application of topical steroid-based creams. J Pediatr Surg. 2005;40:709-12.

91. Jørgensen ET, Svensson A. The treatment of phimosis in boys, with a potent topical steroid (clobetasol propionate $0.05 \%$ ) cream. Acta Derm Venereol. 1993;73:55-6.
92. Lindhagen T. Topical clobetasol propionate compared with placebo in the treatment of unretractable foreskin. Eur J Surg. 1996;162:969-72.

93. Yang SS, Tsai YC, Wu CC, et al. Highly potent and moderately potent topical steroids are effective in treating phimosis: a prospective randomized study. J Urol. 2005;173:1361-3.

94. Ghysel C, Vander Eeckt K, Bogaert GA. Long-term efficiency of skin stretching and a topical corticoid cream application for unretractable foreskin and phimosis in prepubertal boys. Urol Int. 2009;82:81-8.

95. Bunker CB. Comments on the British Association of Dermatologists guidelines for the management of lichen sclerosus. Br J Dermatol. 2011;164:894-5.

96. Fischer G, Bradford J. Topical immunosuppressants, genital lichen sclerosus and the risk of squamous cell carcinoma: a case report. J Reprod Med. 2007;52:329-31.

97. Commission on Human Medicines. Topical tacrolimus (protopic) and pimecrolimus (Elidel): reports of malignancies. Curr Probl Pharmacovigil. 2006;31:1-2.

98. Fistarol SK, Itin PH. Anti-inflammatory treatment. Curr Probl Dermatol. 2011;40:58-70.

99. Yesudian PD. The role of calcineurin inhibitors in the management of lichen sclerosus. Am J Clin Dermatol. 2009;10: $313-8$.

100. Goldstein AT, Marinoff SC, Christopher K. Pimecrolimus for the treatment of vulvar lichen sclerosus in a premenarchal girl. J Pediatr Adolesc Gynecol. 2004;17:35-7.

101. Boms S, Gambichler T, Freitag M, et al. Pimecrolimus $1 \%$ cream for anogenital lichen sclerosus in childhood. BMC Dermatol. 2004;4:14.

102. Goldstein AT, Marinoff SC, Christopher K. Pimecrolimus for the treatment of vulvar lichen sclerosus: a report of 4 cases. J Reprod Med. 2004;49:778-80.

103. Nissi R, Eriksen H, Risteli J, et al. Pimecrolimus cream $1 \%$ in the treatment of lichen sclerosus. Gynecol Obstet Invest. 2007;63:151-4.

104. Oskay T, Sezer HK, Genç C, et al. Pimecrolimus $1 \%$ cream in the treatment of vulvar lichen sclerosus in postmenopausal women. Int J Dermatol. 2007;46:527-32.

105. Nissi R, Kotila V, Knuuti E, et al. Altered p53 and Bcl-2 expression in keratinocytes of vulvar lichen sclerosus during pimecrolimus reatment. Br J Dermatol. 2009;161:958-60.

106. Kauppila S, Kotila V, Knuuti E, et al. The effect of topical pimecrolimus on inflammatory infiltrate in vulvar lichen sclerosus. Am J Obstet Gynecol 2010;202:181.e1-4.

107. Goldstein AT, Creasey A, Pfau R, et al. A double-blind, randomized controlled trial of clobetasol versus pimecrolimus in patients with vulvar lichen sclerosus. J Am Acad Dermatol. 2011;64:e99-104.

108. Kim CY, Kim JG, Oh CW. Treatment of oral lichen sclerosus with $1 \%$ pimecrolimus cream. Ann Dermatol. 2010;22: 326-9.

109. Assmann T, Becker-Wegerich P, Grewe M, et al. Tacrolimus ointment for the treatment of vulvar lichen sclerosus. J Am Acad Dermatol. 2003;48:935-7.

110. Kunstfeld R, Kirnbauer R, Stingl G, et al. Successful treatment of vulvar lichen sclerosus with topical tacrolimus. Arch Dermatol. 2003;139:850-2.

111. Böhm M, Frieling U, Luger TA, et al. Successful treatment of anogenital lichen sclerosus with topical tacrolimus. Arch Dermatol. 2003;139:922-4.

112. Ginarte M, Toribio J. Vulvar lichen sclerosus successfully treated with topical tacrolimus. Eur J Obstet Gynecol Reprod Biol. 2005;123:123-4.

113. Luesley DM, Downey GP. Topical tacrolimus in the management of lichen sclerosus. BJOG. 2006;113:832-4. 
114. Virgili A, Lauriola MM, Mantovani L, et al. Vulvar lichen sclerosus: 11 women treated with tacrolimus $0.1 \%$ ointment. Acta Derm Venereol. 2007;87:69-72.

115. Hengge UR, Krause W, Hofmann H, et al. Multicentre, phase II trial on the safety and efficacy of topical tacrolimus ointment for the treatment of lichen sclerosus. Br J Dermatol. 2006;155: 1021-8.

116. Sotiriou E, Apalla Z, Patsatsi A, et al. Topical tacrolimus for recalcitrant vulvar lichen sclerosus. Eur J Dermatol. 2009;19: $515-6$.

117. Matsumoto Y, Yamamoto T, Isobe T, et al. Successful treatment of vulvar lichen sclerosus in a child with low-concentration topical tacrolimus ointment. J Dermatol. 2007;34:114-6.

118. Sideri M, Origoni M, Spinaci L, et al. Topical testosterone in the treatment of vulvar lichen sclerosus. Int $\mathrm{J}$ Gynaecol Obstet. 1994;46:53-6.

119. Cattaneo A, De Marco A, Sonni L, et al. Clobetasol vs. testosterone in the treatment of lichen sclerosus of the vular region. Minerva Ginecol. 1992;44:567-71.

120. Ayhan A, Guven ES, Guven S, et al. Testosterone versus clobetasol for maintenance of vulvar lichen sclerosus associated with varable degrees of squamous cell hyperplasia. Acta Obstet Gynecol Scand. 2007;86:715-9.

121. Bornstein J, Heifetz S, Kellner Y, et al. Clobetasol dipropionate $0.05 \%$ versus testosterone propionate $2 \%$ topical application for severe vulvar lichen sclerosus. Am J Obstet Gynecol. 1998; 178:80-4.

122. Mangold R, Heilmann V, Rossmanith WG. Iatrogenic androgenization. Zentralbl Gynakol. 1998;120:515-7.

123. Joura EA, Zeisler H, Bancher-Todesca D, et al. Short-term effects of topical testosterone in vulvar lichen sclerosus. Obstet Gynecol. 1997;89:297-9.

124. Parker LU, Bergfeld WF. Virilization secondary to topical testosterone. Cleve Clin J Med. 1991;58:43-6.

125. Ayhan A, Urman B, Yüce K, et al. Topical testosterone for lichen sclerosus. Int J Gynaecol Obstet. 1989;30:253-5.

126. Romppanen U, Tuimala R, Ellmén J, et al. Oral treatment of vulvar dystrophy with an aromatic retinoid, etretinate. Geburtshilfe Frauenheilkd. 1986;46:242-7.

127. Mork NJ, Jensen P, Hoel PS. Vulval lichen sclerosus et atrophicus treated with etretinate (Tigason). Acta Derm Venereol. 1986;66:363-5.

128. Bousema MT, Romppanen U, Geiger JM, et al. Acitretin in the treatment of severe lichen sclerosus et atrophicus of the vulva: a double-blind, placebo-controlled study. J Am Acad Dermatol. 1994;30:225-31.

129. Virgili A, Corazza M, Bianchi A, et al. Open study of topical $0.025 \%$ tretinoin in the treatment of vulvar lichen sclerosus: one year of therapy. J Reprod Med. 1995;40:614-8.

130. Ioannides D, Lazaridou E, Apalla Z, et al. Acitretin for severe lichen sclerosus of male genitalia: a randomized, placebo controlled study. J Urol. 2010;183:1395-9.

131. Kulkarni S, Barbagli G, Kirpekar D, et al. Lichen sclerosus of the male genitalia and urethra: surgical options and results in a multicenter international experience with 215 patients. Eur Urol. 2009;55:945-54.

132. Reichrath J, Reinhold U, Tilgen W. Treatment of genito-anal leisons in inflammatory skin diseases with PUVA cream photochemotherapy: an open pilot study in 12 patients. Dermatology. 2002;205:245-8

133. von Kobyletzki, Freitag M, Hoffmann K, et al. Balneophotochemotherapy with 8-methoxypsoralen in lichen sclerosis et atrophicus. Hautarzt. 1997; 48:488-91.

134. Dalmau J, Baselga E, Roé E, et al. Psoralen-UVA treatment for generalized prepubertal extragenital lichen sclerosus et atrophicus. J Am Acad. 2006;55(2 Suppl.):S56-8.
135. Valdivielso-Ramos M, Bueno C, Hernanz JM. Significant improvement in extensive lichen sclerosus with tacrolimus ointment and PUVA. Am J Clin Dermatol. 2008;9:175-9.

136. Beattie PE, Dawe RS, Ferguson J, et al. UVA1 phototherapy for genital lichen sclerosus. Clin Exp Dermatol. 2006;31:343-7.

137. Kreuter A, Gambichler T, Avermaete A, et al. Low-dose ultraviolet A1 phototherapy for extragenital lichen sclerosus: results of a preliminary study. J Am Acad Dermatol. 2002;46:251-5.

138. Colbert RL, Chiang MP, Carlin CS, et al. Progressive extragenital lichen sclerosus successfully treated with narrowband UV-B phototherapy. Arch Dermatol. 2007;143:19-20.

139. Hillemanns P, Untch M, Pröve F, et al. Photodynamic therapy of vulvar lichen sclerosus with 5-aminolevulinic acid. Obstet Gynecol. 1999;93:71-4.

140. Sotiriou E, Apalla Z, Patsatsi A, et al. Recalcitrant vulvar lichen sclerosis treated with aminolevulinic acid-photodynamic therapy: a report of five cases. J Eur Acad Dermatol Venereol. 2008;22:1398-9.

141. Zawislak AA, McCluggage WG, Donnelly RF, et al. Response of vulval lichen sclerosus and squamous hyperplasia to photodynamic treatment using sustained topical delivery of aminolevulinic acid from a novel bioadhesive patch system. Photodermatol Photoimmunol Photomed. 2009;25:111-3.

142. Sotiriou E, Panagiotidou D, Ioannidis D. An open trial of 5-aminolevulinic acid photodynamic therapy for vulvar lichen sclerosus. Eur J Obstet Gynecol Reprod Biol. 2008;141:187-8.

143. Olejek A, Steplewska K, Gabriel A, et al. Efficacy of photodynamic therapy in vulvar lichen sclerosus treatment based on immunohistochemical analysis of CD34, CD44, myelin basic protein, and Ki67 antibodies. Int J Gynecol Cancer. 2010;20: 879-87.

144. Olejek A, Kozak-Darmas I, Kellas-Sleczka S, et al. Effectiveness of photodynamic therapy in the treatment of lichen sclerosus: cell changes in immunohistochemistry. Neuro Endocrinol Lett. 2009;30:547-51.

145. Hagedorn M, Golüke T, Mall G. Lichen sclerosus and squamous cell carcinoma of the vulva. J Dtsch Dermatol Ges. 2003;1: 864-8.

146. Carli P, Cattaneo A, De Magnis A, et al. Squamous cell carcinoma arising in vulval lichen sclerosus: a longitudinal cohort study. Eur J Cancer Prev. 1995;4:491-5.

147. Jones RW, Sadler L, Grant S, et al. Clinically identifying women with vulvar lichen sclerosus at increased risk of squamous cell carcinoma: a case-control study. J Reprod Med. 2004; 49:808-11.

148. Chiesa-Vottero A, Dvoretsky PM, Hart WR. Histopathologic study of thin vulvar squamous cell carcinomas and associated cutaneous lesions: a correlative study of 48 tumors in 44 patients with analysis of adjacent vulvar intraepithelial neoplasia types and lichen sclerosus. Am J Surg Pathol. 2006;30:310-8.

149. Nasca MR, Innocenzi D, Micali G. Penile cancer among patients with genital lichen sclerosus. J Am Acad Dermatol. 1999;41: 911-4.

150. Micali G, Nasca MR, Innocenzi D. Lichen sclerosus of the glans is significantly associated with penile carcinoma [letter]. Sex Transm Infect. 2001;77:226.

151. Barbagli G, Palminteri E, Mirri F, et al. Penile carcinoma in patients with genital lichen sclerosus: a multicenter survey. J Urol. 2006;175:1359-63.

152. Powell J, Robson A, Cranston D, et al. High incidence of lichen sclerosus in patients with squamous cell carcinoma of the penis. Br J Dermatol. 2001;145:85-9.

153. Perceau G, Derancourt C, Clavel C, et al. Lichen sclerosus is frequently present in penile squamous cell carcinomas but is not always associated with oncogenic human papillomavirus. Br J Dermatol. 2003;148:934-8. 
154. Velazquez EF, Cubilla AL. Lichen sclerosus in 68 patients with squamous cell carcinoma of the penis: frequent atypias and correlation with special carcinoma variants suggests a precancerous role. Am J Surg Pathol. 2003;27:1448-53.

155. Department of Health and Human Services. ODS post-marketing safety review (PID 040754, PID 040752): update on malignancy related events in all age groups. Pimecrolimus (Elidel $^{\circledR}$, NDA 21-302) topical tacrolimus (Protopic ${ }^{\circledR}$, NDA 50-777) [online]. Available from URL: http://www.fda.gov/ ohrms/dockets/ac/05/briefing/2005-4089b2_01_06_Pimecrolimus \%20Tacrolimus\%20Malignancy\%20Update\%20Pitts\%20PID\% 20040754\%20040752.pdf. Accessed 23 Nov 2012. 